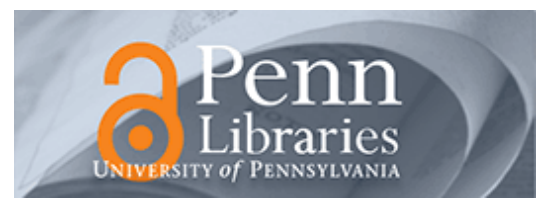

University of Pennsylvania

ScholarlyCommons

Management Papers

Wharton Faculty Research

$12-2006$

\title{
Dynamic Delegation: Shared, Hierarchical, and Deindividualized Leadership in Extreme Action Teams
}

\author{
Katherine J. Klein \\ University of Pennsylvania \\ Jonathan C. Ziegert \\ Andrew P. Knight \\ University of Pennsylvania \\ Yan Xiao
}

Follow this and additional works at: https://repository.upenn.edu/mgmt_papers

Part of the Human Resources Management Commons, and the Organizational Behavior and Theory Commons

\section{Recommended Citation}

Klein, K. J., Ziegert, J. C., Knight, A. P., \& Xiao, Y. (2006). Dynamic Delegation: Shared, Hierarchical, and Deindividualized Leadership in Extreme Action Teams. Administrative Science Quarterly, 51 (4), 590-621. http://dx.doi.org/10.2189/asqu.51.4.590

This paper is posted at ScholarlyCommons. https://repository.upenn.edu/mgmt_papers/73

For more information, please contact repository@pobox.upenn.edu. 


\title{
Dynamic Delegation: Shared, Hierarchical, and Deindividualized Leadership in Extreme Action Teams
}

\author{
Abstract \\ This paper examines the leadership of extreme action teams-teams whose highly skilled members \\ cooperate to perform urgent, unpredictable, interdependent, and highly consequential tasks while \\ simultaneously coping with frequent changes in team composition and training their teams' novice \\ members. Our qualitative investigation of the leadership of extreme action medical teams in an \\ emergency trauma center revealed a hierarchical, deindividualized system of shared leadership. At the \\ heart of this system is dynamic delegation: senior leaders' rapid and repeated delegation of the active \\ leadership role to and withdrawal of the active leadership role from more junior leaders of the team. Our \\ findings suggest that dynamic delegation enhances extreme action teams' ability to perform reliably while \\ also building their novice team members' skills. We highlight the contingencies that guide senior leaders' \\ delegation and withdrawal of the active leadership role, as well as the values and structures that motivate \\ and enable the shared, ongoing practice of dynamic delegation. Further, we suggest that extreme action \\ teams and other "improvisational" organizational units may achieve swift coordination and reliable \\ performance by melding hierarchical and bureaucratic role-based structures with flexibility-enhancing \\ processes. The insights emerging from our findings at once extend and challenge prior leadership theory \\ and research, paving the way for further theory development and research on team leadership in dynamic \\ settings. \\ Disciplines \\ Human Resources Management I Organizational Behavior and Theory
}




\title{
DYNAMIC DELEGATION:
}

\section{SHARED, HIERARCHICAL, AND DEINVIDUALIZED LEADERSHIP \\ IN EXTREME ACTION TEAMS}

\author{
Katherine J. Klein \\ Management Department, The Wharton School, University of Pennsylvania \\ KleinK@wharton.upenn.edu \\ Jonathan C. Ziegert \\ Department of Management, LeBow College of Business, Drexel University \\ Ziegert@drexel.edu \\ Andrew P. Knight \\ Management Department, The Wharton School, University of Pennsylvania \\ KnightA@wharton.upenn.edu \\ and \\ Yan Xiao \\ School of Medicine, University of Maryland, Baltimore \\ YXiao@umaryland.edu
}

We are extremely grateful to the attending surgeons, attending anesthesiologists, fellows, nurses, residents and other members of the participating organization for their involvement in and support of this research. We thank Dan Brass, the three anonymous ASQ reviewers, Andy Cohen, Colin Mackenzie, Virginia Smith Major, Jennifer Mueller, Ben Schneider, Mathis Schulte, Ray Sparrowe, Bob Sutton and the members of the Wharton School's M-Squared group for their insightful and constructive comments on earlier drafts of this manuscript. This research was supported in part by contracts from the Army Research Institute (DASW01-99-K-0003). Opinions expressed in this manuscript are those of the authors. They do not necessarily reflect the official policies or views of the participating organization or the Army Research Institute. 


\title{
DYNAMIC DELEGATION: \\ SHARED, HIERARCHICAL, AND DEINVIDUALIZED LEADERSHIP \\ IN EXTREME ACTION TEAMS
}

\begin{abstract}
How does one simultaneously lead and develop a team composed of experts and novices, many of whom have never worked together before, in performing an uncertain, interdependent, complex and urgent task? Our qualitative investigation of the leadership of such teams resuscitation teams in an emergency trauma center - revealed a hierarchical, deindividualized system of shared leadership. At the heart of this system is dynamic delegation: senior leaders' rapid and repeated delegation of the active leadership role to, and withdrawal of the active leadership role from, more junior leaders of the team. Our findings suggest that dynamic delegation enhances trauma teams' ability to perform reliably while also building their novice team members' skills. We highlight the contingencies that guide senior leaders' delegation and withdrawal of the active leadership role, as well as the unit values and structures that motivate and enable the shared, ongoing practice of dynamic delegation. Further, we posit that dynamic delegation simultaneously reflects and tempers the trauma unit's hierarchical, bureaucratic structure, engendering coordination and flexibility in response to changing task demands.
\end{abstract}




\section{DYNAMIC DELEGATION:}

\section{SHARED, HIERARCHICAL, AND DEINVIDUALIZED LEADERSHIP IN EXTREME ACTION TEAMS}

The patient arrives by helicopter or ambulance at the City Trauma Center, one of the best and busiest trauma care centers in the world. ${ }^{1}$ The victim of a shooting, stabbing, car crash, or some other traumatic blow to the body, the patient is transported to the Center's Trauma Resuscitation Unit (TRU) and is immediately surrounded by a team of doctors, nurses, and technicians. The team's task is to stabilize, diagnose, and treat the patient as quickly as possible. Errors or delays in this process may result in the death of the patient; quick and appropriate treatment is likely to save the patient's life. Several members of the team have never before worked together. Further, some of the doctors are relative novices. They are residents who joined the TRU days ago, seeking additional experience and training; they will leave the organization at the end of the month. Throughout the coming day and night, more patients will arrive, at unpredictable times, bearing unpredictable and uncertain injuries. And throughout the day and night, the team will change repeatedly in composition, as team members end their shifts of varying lengths and are replaced by other members of the TRU. In the months ahead, hundreds of trauma victims will enter the TRU. Scores of residents will cycle through. Evolving interdisciplinary teams of doctors, nurses, and technicians, often unfamiliar to one another, will provide treatment, repeatedly facing tasks necessitating swift coordination, reliable performance, adaptation, and learning.

Clearly, the teams of the TRU face exceptional challenges. They must provide consistent high quality patient care and, at the same time, train and develop their novice members. Their tasks are uncertain, unpredictable, urgent, complex, interdependent, and tightly coupled.

\footnotetext{
${ }^{1}$ City Trauma Center is a pseudonym.
} 
Lacking detailed knowledge of their patient's injuries and history, they must make quick decisions likely to have immediate and significant consequences. And their frequently changing composition limits the extent to which team members can anticipate each other's skills, knowledge, strengths, and habits.

Team leaders are likely to play an important role in building, guiding, and coordinating TRU team members to meet these challenges (Kozlowski et al., 1996; Hackman and Wageman, 2005). But, precisely how does one lead a team whose ultimate goals - high reliability and the development of novice members - may conflict, whose tasks are urgent, unpredictable, complex, and interdependent, and whose membership is ever-changing? Leadership theories currently dominant in the organizational literature - such as transformational leadership theory and leader member exchange theory (e.g., Dansereau, Graen, and Haga, 1975; Bass, 1985; Graen and UhlBien, 1995; Bass, 1998; Avolio, 1999; Schriesheim, Castro, and Cogliser, 1999) - are of limited help in answering these questions. Indeed, they were not designed to do so. Instead, these theories focus primarily on universal leader traits and behaviors designed to enhance follower motivation and commitment (House and Aditya, 1997). Further, these models highlight the dyadic relationship between a leader and a follower, devoting little attention to the role a leader may play in developing and guiding a team of interdependent individuals (Yukl, 1999). Finally, the models rest, implicitly, on the assumption of long-term and largely static leader-follower relationships and leadership effects (Kozlowski et al. 1996).

Yet, many of the characteristics that distinguish TRU teams are likely to become increasingly common in years ahead. As numerous scholars have noted (e.g., Cascio, 2003), the contemporary workplace is evolving rapidly. Work organizations now rely increasingly on cross-functional teams assembled swiftly to tackle urgent and novel issues (Kozlowski and Bell, 
2003). Further, the tempo of work is changing, becoming not only faster, but also more dynamic and unpredictable (Cascio, 2003). Organizational complexity is increasing as well, which, when combined with tighter coupling of work units, necessitates highly reliable team and organizational performance (Perrow, 1984; Weick, Sutcliffe, and Obstfeld, 1999). Finally, the employee-employer relationship is weakening (e. g., Hall and Moss, 1998; Cappelli, 1999). Given increasing employer turnover, long-term employee relationships cannot be assumed (Cappelli, 2000). The TRU teams described above thus present a microcosm - a focalized example - of many of the demands that contemporary organizations increasingly face.

To gain new theoretical insights regarding team leadership in highly dynamic settings, we conducted a qualitative field investigation of the leadership of teams in the TRU. Sundstrom and his colleagues (Sundstrom, De Meuse, and Futrell, 1990: 121) would characterize the teams of the TRU as "action teams" - that is, "highly skilled specialist teams cooperating in brief performance events that require improvisation in unpredictable circumstances.” Yet the action teams of the TRU experience extraordinary demands. We thus characterize these teams as extreme action teams - action teams whose members (a) cooperate to perform urgent, highly consequential tasks; while simultaneously (b) coping with frequent changes in team composition; and (c) training and developing novice team members whose services may be required at any time.

Our findings document a hierarchical, deindividualized, and dynamic system of shared leadership that appears to allow the extreme action teams of the TRU to perform reliably (Weick, Sutcliffe, and Obstfeld, 1999; Bigley and Roberts, 2001) - while also developing their most novice team members' skills. At the heart of this system is dynamic delegation - senior leaders' rapid and repeated delegation of the active leadership role to, and withdrawal of the active 
leadership role from, more junior leaders of the team, in response to changing task demands. The insights emerging from our findings at once recall, extend, and challenge prior leadership theory and research, paving the way for further theory development and research regarding team leadership in dynamic settings. To situate our findings within the leadership literature, we highlight four leadership perspectives of particular relevance to the extreme teams of the TRU. Both older and newer than transformational leadership theory and LMX, these four perspectives offer insights into the structure, process, and purpose of team leadership in the TRU.

\section{Leadership Perspectives: Towards an Understanding of the Leadership of Extreme Teams}

Contingent leadership. Contingency theories of leadership dominated the leadership literature during the 1960s and 1970s. In brief, these theories - such as Fiedler’s least preferred coworker (LPC) theory (Fiedler, 1964; 1967), House’s path goal theory (House, 1971), Vroom and Yetton's normative decision model (Vroom and Yetton, 1973), Hersey and Blanchard's situational leadership theory (1977), and Kerr and Jermier’s substitutes for leadership theory (Kerr and Jermier, 1978) - proposed that situational characteristics moderate the relationship between leader behaviors (such as consideration and initiating structure) and outcomes. Leaders must be matched to, or must match their style to, characteristics of the situation (i.e., the task, subordinates, etc.), these theories emphasized. For example, House's path goal theory urged leaders to provide directive leadership when subordinates are inexperienced and their tasks are unstructured and complex. Vroom and Yetton advised leaders to allow subordinates more influence in decision making if the subordinates share, rather than oppose, organizational goals. And substitutes for leadership theory suggested that a pressing and important task might substitute for, or obviate the need for, a motivating leader. While support for these theories overall has been mixed (Yukl, 2006), we find evidence of a kind of high-speed contingent 
leadership in the TRU, as leader adapt their behaviors to the changing nature of their teams' tasks and to the changing composition of their teams.

Functional team leadership. As research on team-based work structures has burgeoned, an increasing number of researchers have turned their attention to team leadership, often drawing inspiration from McGrath’s (1962:5) observation that the leader’s “main job is to do, or get done, whatever is not being adequately handled for group needs.” Building on this insight, functional leadership models describe the broad functions a leader may serve for his or her team, without specifying precisely how a leader should do so. Key leadership functions identified in this literature (e.g., Kozlowski et al., 1996; Zaccaro, Rittman, and Marks, 2001; Hackman and Wageman, 2005; Morgeson, 2005;) include: (1) monitoring the team’s performance and environment to discern threats to the team's effectiveness; (2) structuring and directing team members' activities; (3) teaching, coaching, and training team members to develop their skills and knowledge; (4) motivating and inspiring team members to enhance their commitment to task accomplishment; and (5) intervening actively in the team's work. The results of research designed to test the functional team leadership perspective (e.g., Morgeson, 2005) are encouraging, although research of this type remains limited. In the TRU, we find team leaders do indeed perform many of these functions.

Shared team leadership. In recent years, a number of scholars have proposed that multiple members of a given team, unit, or organization may enact leadership informally - even in the presence of a formally designated leader (Avolio et al., 1996; Pearce and Sims, 2002; Pearce and Conger; 2003). Conger and Pearce (2003: 286) described shared team leadership as “a dynamic, interactive influence process among individuals in work groups in which the objective is to lead one another to the achievement of group goals.” Research designed to test 
this perspective remains limited, but initial studies document significant positive relationships between shared team leadership and outcomes such as team morale and performance (Avolio et al., 1996; Pearce and Sims, 2002). While our findings do suggest that TRU team leadership is shared, we find a far more structured and hierarchical version of shared leadership than is depicted in this literature stream.

Flexible leadership. Finally, several leadership researchers and theorists have argued that, in times of rapid change, leaders must be highly flexible, responsive, and adaptive. Zaccaro et al. (1991: 317), for example, suggested that "socially intelligent” leaders have the social perceptiveness and behavioral flexibility "to ascertain the demands, requirements, and affordances in organizational problem scenarios and tailor their responses accordingly.” In a similar vein, Denison, Hooijberg, and Quinn (1995: 526) built on Quinn’s (1984) competing values approach to leadership to argue that "effective leaders are those who have the cognitive and behavioral complexity to respond appropriately to a wide range of situations that may in fact require contrary and opposing behaviors.” Yukl and Lepsinger (2004: 203) underscored this perspective, arguing that leaders must display flexibility so that they may "balance competing demands and reconcile tradeoffs among different performance determinants.” The dynamism of the TRU, our findings suggest, requires great flexibility on the part of TRU team leaders. They must adapt their behaviors rapidly and flexibly to changing task conditions and team composition.

\section{The Current Study}

The four leadership perspectives above hint at the nature - contingent, functional, flexible, and shared - of team leadership in the TRU. And yet, the emerging picture remains, not surprisingly, tentative and imprecise. When team composition changes frequently, reliable 
performance of urgent and interdependent tasks is critical, and novice team members must be trained and developed on-the-job, what does leadership look like? How is leadership enacted and by whom?

To address leadership questions such as these, Conger (1998: 109-110) called for process-oriented qualitative research, noting:

Most survey-generated leadership descriptors fail to help us understand the deeper structures of leadership phenomena. We trade-off the "how" and "why" questions about leadership for highly abstracted concepts and descriptions which allow us only to generalize across a range of contexts at relatively superficial levels... The dynamic nature of the leadership process also poses serious challenges for quantitative methods.

Using qualitative research methods, we investigated the deeper structures of extreme action team leadership in the TRU, documenting a shared, hierarchical, deindividualized system of leadership through dynamic delegation. Balancing hierarchy and flexibility, dynamic delegation, we propose, allows leaders operating in rapidly changing, uncertain, high-risk team environments to meet the potentially competing goals of reliable performance and team member development. Below, we describe our research methods and then present and discuss our findings, highlighting the ways in which our findings recall, challenge, and extend prior leadership theory and research.

\section{METHODOLOGICAL APPROACH}

\section{The Research Setting}

The City Trauma Center (CTC) is an urban Level-1 shock trauma center located in the Mid-Atlantic region of the United States that admits more than 7,000 patients each year. The Center primarily treats patients who have sustained major injuries due to car crashes (40 percent); intentional violence (e.g., gunshot or stabbing wounds) (20 percent); 
industrial/agricultural/recreational accidents (20 percent); or falls (20 percent). A significant focus of the CTC is training critical care providers; more than 250 trainees (residents and fellows) rotate through the Center each year.

The primary point of patient entry to the Center - and the focal setting of our research is the Trauma Resuscitation Unit (TRU). In the TRU, the goal of care providers is to stabilize the patient prior to his/her progression to surgery, to in-patient hospital care, or to his/her home. The TRU can be thought of as the "entry gate" to further treatment and care in the CTC. When a patient arrives in the TRU, a team of specialists immediately assembles to receive and treat him or her. This team is typically comprised of: (1) an attending surgeon (a faculty surgeon in the Center with the most trauma surgery experience); (2) a surgical fellow (a physician who has recently completed his/her residency and who has opted to pursue an additional year of training in the Center, during which he/she spends three months supervising residents and medical students in the TRU); (3) three to six Surgery or Emergency Medicine residents (physicians varying in experience who have completed medical school, but not their subsequent years of residency specialty training and who typically work and train in the TRU for a one to two month rotation); (4) an anesthesiologist; (5) a registered nurse; and (6) a trauma technician.

The composition of a TRU treatment team changes frequently as individual team members cycle on and off the team. Team members work shifts of differing lengths. Thus, the make-up of the team that assembles to treat one patient may differ from the make-up a team that assembles to treat a second patient one hour later; some individuals may have completed their shifts while others have just begun theirs. Further, the individuals assigned to perform several of the key roles within the team change from patient to patient. When a patient arrives, a resident 
(the "admitting resident”) and a nurse (the “admitting nurse”) are assigned to treat the patient. When a second patient arrives, a different resident and nurse are assigned to treat that patient. Team composition shifts not only from patient to patient, but also from day to day, week to week, and month to month. Attending surgeons, fellows, residents, nurses, technicians, and specialists work schedules that vary from day to day; an attending, nurse, or technician who works in the TRU one day may not be scheduled to work in the unit again for several days. Further, team composition changes on a weekly and monthly basis as surgical fellows and residents complete their TRU rotations and others begin theirs.

\section{Levels of Analysis}

The focus of our research, given the volatility in the composition of the TRU workforce, is the team that assembles to treat a given patient. The lifetime of each team is quite brief, beginning with the arrival of a patient and ending with that patient's stabilization (typically 15 to 60 minutes). In their shifting composition, TRU teams are rather like airline crews. As the composition of a flight crew may remain the same, shift substantially, or shift entirely from one flight to the next, so the composition of a TRU treatment team may remain the same, shift substantially, or - more rarely - shift entirely from one patient to the next. Treatment teams are nested within the TRU, but at any given time, the TRU is staffed primarily by one team. Multiple teams work sequentially, not simultaneously, in the TRU.

When researchers report that their level of analysis is the team (or in our case, the extreme action or treatment team), they typically seek to examine between-team differences in the phenomenon of interest. But, this was not our goal. Rather, our goal was to identify the commonalities that describe the extreme action teams of the TRU. We thus focused on the roles, structures, norms, and practices that characterized these teams in general, while noting, as 
appropriate, differences among the teams. Such differences were typically attributable to individual differences among the attendings, as we describe in more detail below. Insofar as teams are nested in the TRU, which is in turn nested in the CTC, we consider as well the unit (TRU) and organizational (CTC) contextual characteristics that may shape, guide, or constrain team roles, structures, norms, and practices.

\section{Data Sources}

Guided by recommended strategies for grounded theory development (Miles and Huberman, 1984; Eisenhardt, 1989; Strauss and Corbin, 1990) and recent exemplars of grounded theory development (e.g., Elsbach and Kramer, 1996; Ibarra, 1999; Bigley and Roberts, 2001), we conducted a qualitative investigation of leadership in the TRU, collecting multiple sources of data in two distinct phases. ${ }^{2}$

Phase One data collection. During Phase One, we conducted semi-structured, confidential individual interviews, ranging from 30 to 90 minutes, with 10 members of the TRU (i.e., two attending surgeons, three attending anesthesiologists, two residents, and three nurses). Because the goal was to gain a fundamental understanding of the setting, the TRU teams, and TRU team leadership, we began, as is common in the grounded theory development process (e.g., Spradley, 1979; Pratt, 2000) by asking broad, open-ended questions (e.g., "Who is the leader in the TRU?”). Interviews were audio taped and later transcribed verbatim.

Further, we immersed ourselves in the research setting, spending over 150 hours observing the treatment of approximately 100 different patients in the TRU. We typically stood

\footnotetext{
${ }^{2}$ The first two authors conducted the Phase One and Phase Two interviews and observations. The third author joined the first two authors in sorting and analyzing the data at the conclusion of Phase Two. Eisenhardt (1989) noted that data analysis and interpretation may be strengthened by the involvement of a research team member who did not participate in data collection and who thus lends a fresh eye, and fresh interpretations, to the data. The fourth author served as a point of contact for and entry to the setting and aided in interpreting the data.
} 
at a distance of approximately 10 feet from the patient; this afforded us considerable, although certainly not perfect, ability to see and hear the interactions among the members of the TRU team treating the patient. During slow periods in the TRU, we had informal conversations with TRU physicians, nurses, and technicians. These conversations enhanced our understanding of medical procedures and jargon and of norms and routines in the TRU. While observing, we often took written notes or dictated observations into a tape recorder to document leader behaviors, team member behaviors, or our own general impressions and interpretations. These observations informed and complemented our interviews of individual team members. Our presence as observers did not appear to distract care-givers or arouse their self-consciousness, in part because we dressed, like all the doctors, nurses, and technicians, in surgical scrubs and in part because bystanders (e.g., EMTs, police officers, family members, visiting doctors and nurses) are common in the TRU.

As is common in grounded theory development (e.g., Eisenhardt, 1989; Barley, 1990; Elsbach and Kramer, 1996), we moved back and forth repeatedly between the data and our emerging theoretical ideas. At the conclusion of Phase One, we reviewed all of the interview transcripts and observation notes we had amassed. Taking a break in the data collection process, as others have recommended (Barley, 1990), we had the time and distance to identify key themes and critical gaps in our emerging conceptualization of leadership in the TRU.

Phase Two data sources. Our goal in Phase Two was to collect additional data that would aid us in clarifying, refining, and extending our emerging grounded model of team leadership in extreme action teams. During Phase Two, we interviewed an additional 23 TRU members (six attending surgeons, seven fellows, and ten residents) and spent an additional 100 hours observing the treatment of approximately 75 patients. 
Our Phase Two interviews lasted between 45 and 90 minutes. We explained to interviewees that we had conducted prior research in the TRU and were interested in knowing whether our preliminary conclusions “were on target.” We gave interviewees brief verbal and written overviews of the tentative conclusions drawn from the Phase One research. We then explained to interviewees, "We want to know if we have this right. What do you think of this description of leadership in the TRU? Is there anything you would change or amend?” Verifying one's findings and interpretations with the incumbents of the setting is a commonly recommended strategy in grounded theory development (Glaser and Strauss, 1967; Perlow, 1998; Pratt, 2000).

Approximately 40 percent of interviewees suggested that our conclusions were entirely accurate. For example, a fellow responded, “Yes, I think that's pretty much how I would sum it up. I think you are exactly right...All the things that you summarized that leaders do are there on your list.” The remaining respondents indicated that our Phase One conclusions were quite accurate, but suggested modifications and nuances to our initial model. We then asked a series of questions designed to yield additional information regarding the processes of TRU team leadership and the factors that support and enable these processes. As in Phase One, all interviews were audio taped and later transcribed verbatim.

We supplemented Phase Two interview and observation data with archival data from or about the TRU and the Center and interview transcriptions from a related, but independent TRU study. More specifically, we reviewed the 184-page Resident Training Manual, which describes and explains TRU structure, norms, routines, and guidelines to residents. We observed orientation meetings conducted by attending surgeons, nurses, and other permanent staff members for fellows and residents. And, we examined 32 interview transcriptions from a study 
of TRU team coordination and communication. While these additional sources of data were not central to the further development of our findings and interpretations, they helped to add context to, and enrich our understanding of, the research setting and its dynamics.

\section{Data Sorting, Data Analysis, and Theory Development}

At the conclusion of Phase Two data collection, we reached what Glaser and Strauss (1967) called "theoretical saturation.” That is, we found that new interviews and observation sessions yielded little or no new information. At this point, we halted active data collection and turned our focus to data sorting, data analysis, and theory development.

As is common in grounded theory development (e.g., Ely and Thomas, 2001; Miner, Bassoff, and Moorman, 2001) we first each independently reviewed the Phase One and Phase Two data sets, identifying key themes in the data. Then, we began a series of weekly meetings during which we debated the definitions, merits, and distinctiveness of the themes. Ultimately, we agreed on a set of 70 themes to use in coding the data (e.g., patient condition; changing team composition; hierarchy; surgical tradition; shifting leadership, etc.).

We focused on the interview data - our richest, most detailed, and most voluminous data set. Our primary goal was to reduce the overall volume of qualitative data to a more manageable level by identifying those portions of the interview transcripts that were most relevant to team leadership, the central construct in the dataset. Each interview transcript was coded by at least two of the authors. In coding the interviews, we assigned a maximum of three codes to each chunk of related sentences or “thought unit.” (Currall et al., 1999). We allowed for multiple codes per thought unit because we found that even small thought units could be easily assigned to multiple categories. For example, in response to a question about who is the leader in the TRU, the following answer was coded for "hierarchy”, "nurses”, and "workload”: "Well, 
ideally it would be the fellow or the attending unless there's like 10 patients going on at once. Then it would just be the next most senior person. The nurses are also a big help when it's really busy.” To ensure consistency in our coding process, we met jointly after our independent coding of the interviews to review the codes assigned to each thought unit and resolve any discrepancies. Ultimately, we assigned codes to 1,430 thought units from the interviews.

In the next step of data reduction and processing, we sought to identify the most meaningful pieces of text. To do so, we sorted the thought units by code and then three of the authors read the entire set of thought units pertaining to each code. We each independently reviewed the thought units for each code, noting quotations we deemed exemplary - that is, particularly apt, insightful, and/or likely to generalize beyond our specific research setting. Ultimately, we chose to include for further processing the 545 thought units noted as exemplary by at least two of the first three authors. Finally, we once again reviewed this reduced, but still rich and extensive data base, focusing more intently on identifying the nature of linkages between key themes (e.g., between the quotations regarding "leader monitoring of the team” and those regarding “patient condition”) and on identifying umbrella constructs (e.g., "enabling conditions”) that helped to organize the data. These linkages and umbrella constructs provide the structure for the presentation of our findings, below, and the foundation for the grounded conceptual model that emerges from our results.

\section{FINDINGS: DYNAMIC DELEGATION, HIERARCHY, AND DEINDIVIDUALIZATION}

\section{Who is the Leader of the Extreme Action Teams in the TRU?}

We began our qualitative investigation by asking interviewees, "Who is the leader in the [trauma resuscitation treatment] bay?” Interviewees’ answers surprised and confused us. Based on traditional models of leadership, we expected to receive a simple and straightforward answer 
to this seemingly simple and straightforward question. Instead, respondents' answers were varied and complex. Some reported that there was one leader, but they differed in whom they designated as the one leader. Others reported that there were two leaders. Most, however, reported that there were three leaders, as evidenced by the following quote and additional quotes in Table 1:

The attending surgeon is the leader and then the fellow should be next in charge. Every patient has an admitting resident. The resident's supposed to give orders - to tell other residents what to do. There's kind of a system of checks and balances among the residents, the fellow, and the attending. $(\mathrm{N} 1)^{3}$

Insert Table 1 About Here

We concluded, as this Phase One interviewee suggested and Phase Two interviewees and observations subsequently verified, that the TRU invests leadership in three key positions: the attending surgeon, the fellow, and the admitting resident.

Two aspects of this conclusion are striking. First, TRU team leadership is not invested in one or more individuals but in positions: the attending, fellow, and admitting resident. Indeed, interviewees very rarely commented on the actions of specific individuals by name ("Dr X usually will...”), but instead emphasized the prototypical behaviors of position incumbents (“The attending usually will ...”” or "The fellow will...”). In this sense, leadership in the TRU teams is deindividualized - a function not so much of individual differences and unique dyadic

\footnotetext{
${ }^{3}$ Following each quotation in the text and tables, we show a code in parentheses to indicate the identity of the interviewee: $\mathrm{A}=$ Attending; $\mathrm{F}=$ Fellow; $\mathrm{N}=$ Nurse, $\mathrm{R}=$ Resident. The number following the letter indicates the specific individual respondent, for example R1 is one resident, R2 is a second resident, and so on.
} 
relationships, but of legitimized, even institutionalized, positions and relationships. ${ }^{4}$ Given frequent turnover within TRU teams, the deindividualized nature of leadership seems not only adaptive but necessary. The investment of leadership in a position, rather than in a given individual, recalls Weber's (1947) ideal bureaucracy. Yet, intriguingly, the TRU displays little of the inflexibility commonly deemed characteristic of bureaucracies in practice. We return to this point in the discussion.

Second, TRU team leadership is invested in multiple positions; it is shared. Leadership is not, however, shared informally by all or most team members. Rather, it is invested formally in three positions, suggesting a more rigidly structured system of leadership than the ad hoc, emergent form of shared team leadership emphasized in recent writings (Avolio et al., 1996;

Pearce and Sims, 2002; Pearce and Conger, 2003).

\section{What Do Extreme Action Team Leaders Do?}

During the initial phase of our qualitative investigation, we sought also to identify the key functions performed by leaders in the bay. In discussing what TRU leaders do, interviewees typically described four key functions, which we observed as well. Each of the four functions, summarized in Table 1, may be fulfilled by the attending, the fellow, or the admitting resident. Team leaders provide strategic direction by telling other team members the overall plan or strategy for treating the patient, prioritizing possible interventions (e.g., which injury to treat first), and revising the treatment plan as new information becomes available (e.g., when a previously unknown internal injury is discovered). Second, team leaders monitor the performance of the team by watching and sometimes questioning team members’ performance to

\footnotetext{
${ }^{4}$ It is important not to confuse “deindividualization,” as we use the term with depersonalization, dehumanization, or deindividuation. What we observed in the TRU was not a loss of self, or of dignity, on the part of TRU members, but rather a reliance on roles and positions - rather than personal traits, competencies, or history - to shape and define interpersonal relationships.
} 
ensure that the team makes no serious errors in treating the patient. Monitoring may be close and quite active (e.g., the fellow stands just behind the admitting resident, asking the resident questions such as “What do you want to do as far as x-rays are concerned?”). Or, monitoring may be more distant and passive (e.g., the fellow observes the admitting resident for a brief moment, then walks away to do other work, returning periodically to observe and question the admitting resident). Third, team leaders teach team members by actively giving instruction on how to perform specific medical procedures. For example, we often observed team leaders (e.g., the admitting resident) teaching less experienced members of the team (e.g., more junior residents, or medical students) how to conduct specific patient care procedures. Finally, team leaders provide hands-on treatment of the patient when they assist directly in patient care, typically by performing the team’s most critical and complex medical procedures.

These four functions match those we identified in the functional team leadership literature: structuring and directing team members’ activities, monitoring the team, teaching and developing team members; and actively intervening in the team’s work (e.g., Kozlowski et al., 1996; Hackman and Wageman, 2005; Morgeson, 2005). Notably missing from TRU leaders’ functions is one that figures prominently in the functional leadership literature, as well as in virtually all leadership models: ensuring that team members are motivated and engaged. As is often the case in high reliability organizations (e.g., Bierly and Spender, 1995), TRU team members’ work - saving trauma patients’ lives - is inherently motivating. Thus, TRU team leaders need not fill this function - a conclusion anticipated decades ago by contingency theories of leadership such as House’s (1971) path-goal model and Kerr and Jermier’s (1978) substitutes for leadership theory. 


\section{What is the Active Leadership Role?}

Trauma team leadership resides in no single individual or position, as we have noted. In this sense, extreme action team leadership is shared. But, active leadership of an extreme action team is rarely if ever shared simultaneously. At any given moment, one leader - not three - is expected to be in the active leadership role, actively guiding the team's treatment of the patient. The leadership function most critical to the active leadership role is the provision of strategic direction. The active leader provides strategic guidance for the team, directing the team's focus and procedures during moments of choice or uncertainty. One fellow explained, for example:

During a code, when someone is dying right in front of you, if there is not a leader there, it just runs horribly. You can feel it. Everyone is looking for someone to speak up or say something. As soon as one person says it, the attention focuses there and all the nurses start taking the person’s orders and everything just starts working better. (F6)

A resident noted:

I think in trauma you need the person who's in the press box of the football game - a leader who stands back and watches and sees the errors on the whole field. I mean, the leader should stand there and hear others’ assessments. The leader should be taking in the information and making the decisions as far as strategic direction and what needs to be done. (R9)

The active team leader is not necessarily the most senior or expert leader present on the team. We often observed one leader directing team members’ actions and providing hands-on care of the patient, while a second, more experienced leader stood back, perhaps four or eight feet from the patient, observing patient care and saying nothing. In this case, the first leader is in the active leadership role, as we define the term. 
TRU team members' insistence that the active leadership role should be clearly and demonstrably filled by one person at a time - not three people simultaneously - suggests, as we have noted, a more prescribed and delimited model of shared team leadership than the frameworks presented in recent writings describing the benefits of multiple team members engaged in simultaneous and mutual co-leadership (e.g., Avolio et al., 1996; Pearce and Conger, 2003). Indeed, the TRU norm recalls Vroom and Jago’s (1988) revision of Vroom and Yetton's (1973) contingency model of leader decision-making. When time is of the essence, as it usually is during trauma patient care, relatively autocratic decision-making is most appropriate, Vroom and Jago advised. When time constraints are few, consultative or consensus decision-making may be more appropriate, they proposed. The intriguing TRU variation is to advocate autocratic decision making at virtually all times - but not necessarily autocratic decision-making by the most senior and expert leader of the team. Still, as we describe below, autocratic decisionmaking by junior leaders occurs in the TRU only with the implicit or explicit approval of more senior leaders.

\section{How, When, and Why Does the Active Leadership Role Shift from One Position to}

\section{Another?}

The leadership hierarchy. The three potential active leaders of the trauma team - the attending, the fellow, and the admitting resident - differ in expertise, experience, and tenure in the TRU. They are ranked in a clear and rigid hierarchy, in which the attending has more expertise, experience, status and power than the fellow, who has more expertise, experience, status and power than the admitting resident. Table 2 provides a sample of relevant quotations from our interviews. This hierarchy has profound implications for the movement of the active leadership role among the three leadership positions. One attending surgeon explained: 
Many individuals have the leadership role in question, but there is a very rigid hierarchy underlying that. The flow is one way. The fellow can always supersede the resident, but the resident can't supersede the fellow. The attending can always supersede the fellow and the resident, but neither one of them can supersede the attending. (A5)

Insert Table 2 About Here

Thus, as we clarify below, less senior leaders fulfill the active leadership role in the team when more senior leaders are either absent (e.g., caring for another patient) or when more senior leaders have explicitly or implicitly delegated the role to a more junior leader. Summarizing the hierarchy from attending, to fellow, to resident, a fellow commented, "How many years have you trained? You win if you have more than the other person (F3).” A nurse explained, “The attending is the general. The fellow is like the colonel, telling the residents what's expected of them. The residents - some are like lieutenants and some are buck privates (N1).”

Dynamic delegation. Despite the rigid hierarchy described by attendings, fellows, residents, and nurses, the active leadership role may shift up and down the leadership hierarchy over the course of a fellow's or resident's tenure in the TRU, or even during the care of a single patient. A shift in active leadership occurs when a senior leader (the attending or the fellow) takes over strategic direction of the team, assuming a more active and influential role in the team, or, conversely, when a senior leader recedes from strategic direction, assuming a more passive role and implicitly or explicitly delegating the active leadership role to a more junior leader.

Consider the treatment that we observed of the victim of a car accident. The patient arrived by helicopter and was immediately surrounded by the trauma team. The attending 
surgeon strolled into the TRU a few minutes after the patient's arrival. He glanced at the team and the patient, said nothing, grabbed a chair and slouched there, approximately eight feet from the foot of the patient's bed, drinking a soda and making notes in a chart. A few minutes later, when the patient moaned a few times in pain, the attending surgeon put down his soda and notes, got up, strode to the patient's bedside, stood right next to the fellow, queried the fellow for a moment, directed the team to perform specific tests and procedures, and then returned to his chair, soda, and notes, apparently confident of the team's ability to treat the patient's injuries without his further involvement. In this incident - typical of many of the patient care episodes we observed - active leadership shifted, in a matter of minutes, from the fellow (when the attending surgeon was initially slouched in his chair, drinking a soda), to the attending (when the attending stood at the bedside, directing the team), and back to the fellow (when the attending returned to the chair).

Interviewees described these shifts at length. Table 2 provides examples, from our interviews, of the fluid transfer of leadership. Some leadership shifts occur relatively slowly, over a period of days, weeks, or even months. Thus, for example, an attending noted:

There's a reward for being a really good fellow. It is have the attending back off. That's how you know if the fellow is doing a good job - when the attending pokes his head around the door, sees that you've got everything under control, and goes back and sits down at his computer and starts looking at something else. (A5)

Other shifts in leadership are more frequent, occurring during the initial treatment of a patient. For example, a fellow commented:

It's kind of like a student driver or student pilot. In other words, the fellow or the attending would be sitting in the seat with the joystick between their legs and/or the brake 
and so they let the student [the admitting resident] drive or fly the plane. But, the moment there is any turbulence or hazard on the road, it is relatively smooth to transition back and take the controls. So, the resident would feel like they were in this leadership position, but it is a protected leadership role. You try to give them enough rope to hang themselves but not enough to hang the patient. (F2)

In such cases, the transition of leadership is quite seamless, as a resident described:

Sometimes when I'm treating the patient, the fellow or attending will come right over my shoulder or right beside me. They make their presence known and I just step out of the way so they can have access to the patient. Sometimes they'll just stand where they are and ask the patient questions. If the patient needs something quickly, a lot of times the fellow or the attending - it depends on whoever's the closest to a pair of sterile gloves will jump in and make a decision. (R10)

Leadership, in each of these instances, seems to be a baton, whose possession is controlled by the most senior members of the hierarchy. These individuals may assume control, taking possession of the baton, at any time. Yet, often they relinquish possession of the baton to those lower in the hierarchy, although they are likely to stay at arm's length - figuratively, but sometimes literally - from possession of the baton. We refer to senior leaders' passing and reclaiming of the active leadership role as dynamic delegation.

Although scholars often describe delegation as an important and effective leadership behavior (e.g., Bauer and Green, 1996; Yukl and Fu, 1999), delegation has been the focus of surprisingly little theory and research within the academic literature. Bass (1990: 909) noted that “Delegation remains a relatively unexplored management option despite the evidence of important contribution to organization effectiveness.” Leana’s (1986; 1987) work stands in 
contrast to this general rule. Carefully distinguishing participative decision making, the subject of considerable academic theory and research, from delegation, Leana (1987: 229) noted:

Although participation entails subordinate collaboration in decision making, delegation refers to the actual passing of decision-making authority from superior to subordinate ... Participation is always a dyadic or group decision-making process, whereas delegation typically entails decision making by an individual.

Discussions of delegation in the academic literature appear to rest on two key assumptions. The first assumption is that "delegation involves the assignment of new responsibilities to subordinates and additional authority to carry them out” (Yukl, 2006: 98). That is, the superior delegates authority and responsibility for specific, delimited tasks to the subordinate. The second assumption is that delegation is ongoing: Once a superior has passed decision-making authority to a subordinate, he or she does not, and should not, rescind it. Indeed, Yukl (2006: 107) advised, “It is important to avoid reverse delegation, in which control is reasserted over a task that was previously delegated.”

To a considerable extent, dynamic delegation in the TRU teams contradicts both of these assumptions. Senior leaders explicitly or implicitly delegate the active leadership of the team to junior physicians - not just a specific, delimited task, such as inserting a central line or interpreting an ultrasound. Further, our observations and interviews in the TRU suggest that delegation is often transitory - fleeting and flexible. Senior leaders repeatedly and rapidly delegate, and withdraw delegation of, the active leadership role. We turn now to a description of the contingencies that shape senior leaders' delegation of the active leadership role to, and reverse delegation of the active leadership role from, more junior leaders. 
The contingencies that guide dynamic delegation. In observing and interviewing TRU members, we identified three factors that together appear to guide senior leaders' delegation of the active leadership role to, or retraction of the active leadership role from, more junior leaders: (1) patient condition; (2) individual differences among the attendings and fellows; and (3) confidence in self and others. Table 3 provides a sample of relevant quotations from our interviews regarding these topics.

Insert Table 3 About Here

Two key dimensions of patient condition - urgency and novelty - emerged from our observations and interviews as key influences on dynamic delegation. Urgency refers to the extent to which the patient's condition necessitates immediate intervention to save the patient's life. Novelty refers to the extent to which the patient's condition is unfamiliar (non-routine) to caregivers, especially residents. The greater the urgency and novelty of a patient's condition, the more likely the attending or fellow is to take the active leadership role during patient treatment, giving strategic direction, providing hands-on care of the patient, and/or monitoring the team closely. Numerous interviewees described this pattern. As one fellow explained:

When the patient is crashing, the attending takes the leadership from the other ones because it's life and death. When it's routine, the attending kind of steps back and lets the fellow run it. The fellow does the same thing with the residents. (F1) Conversely, when the patient's condition is low in urgency and novelty (for the TRU), senior leaders are likely to step back, effectively delegating active leadership of the team to the 
admitting resident. The admitting resident provides strategic direction to the team and hands-on care of the patient. The fellow is likely to monitor the team from a short distance, watching the team without comment. The attending is likely to move away entirely, neither watching nor communicating with the team in any way.

While the condition of the patient is highly influential, individual differences among the attendings and fellows also affect the display of leadership within a team. Our observations and interviewees’ comments made clear that the attending surgeon, as the most expert and senior member of the team, has the right (and obligation) to intervene in patient care, assuming the active leadership role, as he/she sees fit. The fellow has the right to intervene in patient care, taking over the active leadership role from the admitting resident, but not from the attending surgeon. The extent to which the attendings and fellows do intervene depends in part on their personal style, or desire for control. Interviewees described some attendings and fellows as “micromanagers,” “Type A,” and "hands-on,” and other attendings and fellows as "laid back,” “Type B,” and "hands-off.” The more an attending or fellow is “Type A” and "hands-on,” the more likely he or she is to provide close verbal and physical monitoring of the team, to provide strategic direction to the team, and/or to carry out key medical procedures him or herself. In contrast, the more an attending or fellow is "Type B" and "hands-off," the more likely he or she is to delegate the active leadership role, allowing others more junior in the hierarchy to provide strategic direction and to perform key medical procedures.

Finally, the more confidence the attending has in the fellow's abilities, the more likely the attending is to delegate leadership of patient care to the fellow. Similarly, the more confidence the fellow has in the attending resident, the more likely the fellow is to delegate the active leadership role to the resident. An attending explained: 
Suppose two patients come in at the same time. I have to ask myself, "How much can I trust the fellow to totally manage one patient while I manage the other?” And it really boils down to whether I can trust them alone for the next ten minutes when I'm totally involved with another patient. (A8)

Intriguingly, interviewees suggested that attendings and fellows must not only be confident in the abilities of those lower in the hierarchy, they must also have confidence in their own ability to rectify any mistakes made by those lower in the hierarchy:

In a surgical procedure, the confident surgeon will allow the resident or fellow to do more because the confident surgeon knows that he or she can get them out of it. It takes a lot of confidence to do that. (A2)

In sum, the more routine and less urgent the patient's injuries and the less controlling the attending's personal leadership style, the more likely the attending is to delegate the active leadership role to the fellow. These tendencies are moderated by the attending's confidence in the fellow and by his/her confidence in his/her own abilities to correct and overcome any errors in patient care that the fellow might make. Similarly, fellows are more likely to delegate the active leadership role if the patient's injuries are routine and low in urgency, if the fellow is not highly controlling, and if the fellow has substantial confidence in the residents and in his/her own ability to remedy any treatment errors the residents might make.

Earlier, we described the active leadership role as a baton, but the TRU leadership system, as a whole, is perhaps more aptly described not as a relay race, but as a dance in which the three team leaders step forward or back in response to the patient's changing condition and to the actions, competence, and confidence of others in the leadership hierarchy. The picture that 
emerges from this description is far more dynamic than that of traditional leadership models. In the TRU, leadership is dynamic - a system, or dance, of moving parts.

The rules - or contingencies - that guide the dance of dynamic delegation in the TRU mirror, to a substantial extent, the correlates of delegation identified in Leana's (1986; 1987) research. Leana (1987) studied a large insurance company, using the dollar level of authority exercised by adjusters to settle claims as a measure of supervisors' delegation to each adjuster. As we found that delegation was less likely the more serious (urgent and novel) the patient's condition, so Leana (1987) found that the importance of the decision was negatively related to delegation. Further, as we found that delegation was most likely when senior leaders were confident of junior leaders’ ability, so Leana (1987) found that delegation was significantly positively related to both supervisor trust in the subordinate and an objective measure of subordinate work competence. Leana (1987) did not find a significant effect of supervisor personality or disposition to share authority on delegation, but other researchers (Ashour and England, 1972) have found a significant relationship between leader dominance (a personality trait) and leader delegation of discretionary tasks.

While our findings mirror many of Leana’s and others’ (e.g., House, 1971) conclusions, the dynamic quality of delegation in the TRU is distinctive, as is the frequency of reverse delegation. Relative to the picture of delegation presented in Leana’s and others' writings (Leana, 1986; 1987; Yukl, 2006), delegation in the TRU proceeds at high speed, as attendings and fellows rapidly adjust their delegation decisions in response to actual or perceived patient condition, which may change rapidly during the patient's initial treatment in the TRU. 
In the complex and dynamic dance of delegation, leaders would, it seems, often step on one another's toes. Surely the system could engender considerable conflict among the leaders and frequent mistakes in patient care. Admitting residents and fellows might resent and resist the intervention of attendings who interrupt and take over care of the patient. Attendings might resent and resist the expectation that they stand idly by, watching less experienced doctors perform tasks that the attendings could themselves perform more efficiently. Attendings might overestimate the experience and competence of the fellows, or fellows overestimate the experience and competence of the residents, resulting in grievous errors. Further, residents and other team members might question fellows' and attendings’ authority and decision-making, delaying treatment of the patient.

We observed, and interviewees described, few such conflicts and errors, however. Our data suggested that a set of three enabling conditions - (1) routines, tradition, and values; (2) expert support staff; and (3) time awareness - complement and reinforce the leadership system, reducing the likelihood of conflict and error and thereby enhancing the likelihood of reliable performance, coordination and learning. Table 4 provides a sample of relevant quotations from our interviews.

Insert Table 4 About Here

Routines, tradition, and values within the Center. A set of routines, traditions, and values serve to structure, explain, and justify interactions within the trauma teams we studied, reducing opportunities for conflict and error. Although the treatment of trauma patients is inherently unpredictable and uncertain, a series of routines or protocols guide and organize the team's 
initial activities. These routines are detailed in the Advanced Trauma Life Support (ATLS) manual, published by the American College of Surgeons. An attending anesthesiologist described the ATLS as "the handbook we are singing from during the first ten minutes of any resuscitation" and noted that "most of the attending surgeons here wrote it and teach it” (A1). The ATLS and other Center protocols ensure that, at least in relatively routine cases of traumatic injury, treatment priorities and strategies are well established. This facilitates coordination and enhances fellows' and attendings' comfort in delegating the design and delivery of patient care to residents. Further, the availability of clear routines reduces the likelihood of errors. Finally, residents' and fellows' knowledge that Center attendings contributed to the ATLS enhances their respect for the attendings and their acceptance of attendings’ interventions.

The TRU's leadership system is also bolstered by surgical tradition. Interviewees described the attending's position of hierarchical authority as "ingrained in every surgeon in the operating room” (A3), "the way it is done in surgery" (R1), and "part of the culture of medicine” (A5). Explaining this tradition, interviewees emphasized the dangers associated with a lack of clear leadership: “Patients suffer without leadership. If you do a democracy, patients will suffer. You don't take a vote on what to do with the patient” (F7). In short, TRU team members expect and value hierarchical leadership and authority. At the same time, interviewees emphasized that surgical tradition enshrines teaching. The traditional mantra of surgical training is to "see one, do one, teach one" - that is, to see a procedure, do one (or more), and then teach others to do the procedure (Katz, 1999). This reinforces the expectation that senior leaders delegate to more junior leaders, as junior leaders learn by (monitored) doing.

Center values further legitimate the shared, hierarchical, and deindividualized leadership system. Interviewees emphasized two key values: quality of patient treatment (reliability) and 
training (capacity building). Quality of patient treatment is preeminent - the ultimate goal, "what we are here for" (F6), as one fellow put it. An attending commented, "It's the focus on the care of the injured that makes this place great. There's no other place in the country that is so focused on a particular kind of patient” (A6). At the same time, the focus on patient treatment is balanced and complemented by a commitment to the training of fellows and residents within the TRU. An attending noted: “One of our primary purposes in taking care of patients is training residents and fellows along the way. It's a real balance between patient care and education” (A3). The commitment to quality of patient care enhances team members' acceptance of attendings' and fellows' interventions; those lower in the hierarchy know that more senior leaders' interventions are motivated by concerns for patient well-being. At the same time, the commitment to training motivates attendings and fellows to cede control of patient care to the less experienced members of the team.

The routines, traditions, and values we have described above limit and institutionalize the enactment of leadership within extreme action teams. Much of the organizational literature on leadership emphasizes the influence that leaders have on organizational and unit routines, values, and traditions (e.g., Schein, 1991). But, our findings in the TRU suggest that the causal arrow may also run in the opposite direction. Leaders in the TRU are, to a considerable extent, transients in the setting. Even the attending surgeons are not a constant presence. (On average, each attending works about 60-80 hours per month in the TRU - a limited number of hours given that the TRU is staffed 24 hours a day, 7 days a week, or approximately 744 hours a month.) Organizational and unit routines, values, and traditions play a substantial role in structuring and guiding individual leaders' behaviors in the TRU. In their inductive study of emergency response teams, Bigley and Roberts (2001) reached a similar conclusion; they too emphasized 
the importance of shared values and structured routines for reducing the potential for conflict and chaos within a rapidly-assembled organizational system.

Expert support staff: The nurses. When we asked interviewees to describe how the TRU differs from other trauma care centers and emergency rooms, many extolled the experience, competence, and empowerment of TRU nurses. Interviewees described the TRU as "nurse strong” and emphasized that TRU nurses "have an incredibly high level of knowledge” and "are valued and given a lot of freedom.” Nurses are lower in the formal hierarchy than are residents, but nurses exert considerable informal influence over trauma care, and particularly over the residents. Attendings sanction and value nurses’ role. As one attending put it:

There's sort of like a blank check order form that, as the attending physician, I'll sign and assume the responsibility for their actions, saying that this would have been an order of mine. It is unique. In our TRU, the nurses act almost independently under our orders. (A7)

TRU nurses' power in the TRU rankles some residents. But, fellows and attendings discount residents’ complaints. A fellow commented:

I tell new residents, "Your nurse is your best friend. The day that you understand that and accept that and respect that will be the day that you do well here.” (F5)

The presence of highly skilled, experienced, and empowered nurses provides an additional layer of redundancy, a frequently-highlighted characteristic of high reliability organizations (Roberts, 1990), reducing the likelihood of medical errors. At the same time, fellows' and attendings' knowledge that nurses can and do monitor the quality of residents' work enhances fellows' and attendings' comfort in delegating patient care to residents. An attending summarized: 
The nurses here protect the patients. They know more than most of the residents they're working with. They will come and get the attending if the residents are screwing up, or they'll tell the residents to stop screwing up directly. Every single month, the residents complain that the nurses in the TRU have too much freedom and too much power. But the nurses need it, because how else are they going to protect the patients? (A5) Awareness of time structure and turnover. A final factor that supports and facilitates dynamic delegation in the TRU is awareness of time structure and turnover - TRU members' conscious awareness of the transience of their experiences in the TRU. Residents know that their time in the TRU is limited to just one or two months. Moreover, they know that, in due time, they will become fellows, if they choose to do so, and attendings. Fellows know that they will spend just three months in the TRU and a year in total in the Center, after which they will become attendings. And, attendings and nurses know that residents come and go each month and that fellows come and go each year. For example, a fellow commented:

When there's friction between a fellow and an attending, the fellow just has to wait until the end of the month or the week, because you know that the attendings change every week. So, you just say, "What the hell.” You get by. (F6)

Further, a nurse reported:

Often times, we'll pick this month’s dumbest team of residents. Everyone will say, “My God, I can’t wait for this batch to leave.” We have had 36 groups of residents in the last year and there have probably been three or four months when everybody was just counting the days (N2).

Such awareness of the predictable passage of time, and with it predictable turnover, enhances junior leaders’ acceptance of senior leaders' interventions. Junior leaders know that 
they will not always work under the specific leader whom they find difficult. Moreover, they know that their own time will come - that they will gain positions of greater enduring authority at the end of their residency or fellowship. Similarly, awareness of time structure and turnover enhances senior leaders' tolerance of the junior leaders whom they supervise. A difficult subordinate is likely to be out of the TRU by the end of the month.

Attendings also see benefits from the frequent and predictable turnover of residents and fellows in the TRU:

You can meet a lot of different people and you can learn a lot of different things. They will say, "We would never do this," and you kind of explain why we do things here a certain way. It's more interesting than the same people doing the same thing all the time. (A2)

Further, turnover among residents and fellows increases attendings’ vigilance and hence their reliability:

This constant short rotation of the residents and fellows for a month or two can be very disruptive at times, but it keeps you on your toes and prevents you from falling into the same lull so to speak. I examine all of the patients myself. I look at all the films myself. I look at all the lab work myself. (A4)

Fellows' and residents' awareness of the passage of time, and more specifically, of the strict and quite predictable schedule that governs the stages of their medical training recalls Van Maanen and Schein's (1979) description of fixed (vs. variable) and serial (vs. disjunctive) socialization strategies. In a fixed process, new organizational members know with a high degree of certainty the time it takes to progress through specific socialization stages (e.g., stages in a surgical residency program). And so, whereas variable socialization processes "keep a recruit 
maximally off balance," fixed processes, like those in the TRU, allow recruits to "gear themselves to the situation better” (Van Maanen and Schein, 1979: 247). In a serial process, organizational veterans "groom newcomers who are about to assume similar kinds of positions in the organization” (Van Maanen and Schein, 1979: 247). Serial socialization processes allow recruits to "gain a surer sense of the future by seeing in their more experienced elders an image of themselves further along in the organization” (Van Maanen and Schein, 1979: 247). Nurses’ and attendings' awareness of time structure and turnover appears to allow them, too, to gear themselves to the situation better. Further, the near constant influx of newcomers enhances their vigilance and their learning.

\section{DISCUSSION}

The extreme action teams of the TRU face daunting challenges. Composed of a frequently changing array of experts, novices, and support staff, the teams perform tasks of great urgency, complexity, and uncertainty. Our findings suggest that a hierarchical, deindividualized, and dynamic system of shared leadership enhances these teams’ ability to perform reliably while also building their novice team members’ skills.

Below, we discuss the conceptual implications of our findings. Given the complexity and richness of the TRU leadership system, we consider the system from three vantage points. Like differing focal lengths of a camera's zoom lens, the three vantage points offer distinct, yet complementary views of the same phenomena. We begin by zooming in to take a close-up view of dynamic delegation. From this vantage point, we focus on dynamic delegation from moment to moment, highlighting the contingencies that shape an individual leader's decisions to delegate the active leadership role to more junior leaders at one moment, and to withdraw delegation at the next. We then pull back, widening our figurative camera lens, to examine the unit context 
that motivates and enables the shared, ongoing practice of dynamic delegation among a unit's leaders. This vantage point allows us to identify potential unit-level antecedents and consequences not of a single leader's moment-to-moment delegation or withdrawal of the active leadership role, but of the shared and repeated practice of dynamic delegation among a unit's leaders. Finally, we pull back once again, widening our figurative camera lens still further, to expose the similarities between the TRU's rigidly hierarchical yet fluidly flexible leadership system and the practices of other improvisational organizations - organizations whose membership is fleeting and whose tasks are complex and interdependent. This vantage point allows us to consider dynamic delegation as an exemplar of the mechanisms that improvisational organizations may use to achieve the benefits, and minimize the possible drawbacks, of rolebased, hierarchical bureaucracy. Together, the three vantage points yield an in-depth and multifaceted conceptualization of dynamic delegation. Following our presentation of the three vantage points, we note key limitations of our research and suggest new research directions that may begin to overcome these limitations while testing and extending our findings.

\section{Leader Dynamic Delegation from Moment to Moment: A Contingency Perspective}

Within the TRU, three leaders - the attending, the fellow, and the admitting resident - are arrayed in an explicit hierarchy of expertise and experience. At any given moment, one of these three leaders fills the active leadership role, providing strategic direction and ensuring coordination among team members. He or she may also monitor the team, teach team members information or skills that they lack, and/or step in to provide hands-on care of the patient, as needed. The active leadership role, we found, shifts from moment to moment among the attending, fellow, and admitting resident as a function of the dynamic delegation process. Senior leaders delegate the active leadership role to junior leaders of the team, or withdraw 
delegation, in response to their changing perceptions of: (a) the characteristics of the task (the patient's condition); (b) the junior leader's relevant skills and knowledge; and (c) their own relevant skills and knowledge. The more urgent and novel a senior leader perceives a patient's condition to be, the more likely the senior leader is to assume or retain the active leadership role, and the less likely he or she is to delegate the role. The more confident the senior leader is of the junior leader's skills, or of his or her own skills in correcting any error the junior leader might commit, the more likely the senior leader is to delegate the active leadership role. The senior leader’s perceptions are tempered in part by his or her personal style. Some leaders are “controlling micro-managers,” while others are "laid back.” These tendencies are likely to color the senior leaders' perceptions of the urgency and novelty of the patient's condition, of the junior leaders’ skills, and of their own skills in correcting junior leaders' errors.

This description of the dynamic delegation process recalls the contingency perspective embodied in leadership theories prominent during the 1970s, such as Fiedler's $(1964 ; 1967)$ least preferred coworker (LPC) theory, Vroom and Yetton’s normative decision model (1973), Hersey and Blanchard's situational leadership theory (1977), and House’s path goal theory (1971). As these theories suggested that the most appropriate style of leadership varied as a function of the characteristics of the task, of the subordinates, or of the leader, so our findings suggest that delegation is most appropriate when subordinates’ tasks are low in urgency and novelty, when subordinates' skills and behaviors are confidence-inspiring, and when senior leaders are most confident of their ability to rectify any errors that their subordinates commit (see also Leana, 1987). Our findings thus underscore the central message of contingency theories of leadership: There is no single best style or form of leadership - it depends. 
In several respects, however, our conceptualization of the dynamic delegation process goes beyond extant theory to challenge core assumptions of the traditional contingency leadership perspective. First, the conceptual model emerging from our findings focuses on a leadership behavior - delegation - largely overlooked in traditional contingency theories of leadership. The contingency models of the 1970s focused, for the most part, on the contingencies governing the most effective use of relationship-oriented leadership behaviors (e.g., consideration) versus task-oriented behaviors (e.g., initiating structure) (e.g., Fiedler, 1971; House, 1971; Hersey and Blanchard, 1977). Vroom and Yetton’s decision process theory (1973), another contingency model of this period, described the contingencies governing the effective use of participative decision making. But, as Leana (1987) made clear, participation and delegation are quite distinct. Participation is characterized by "power sharing” and is driven primarily by a leader's desire to enhance subordinates' collaborative contributions and sense of belonging (Leana, 1987: 228-229). In contrast, delegation is characterized by “power relinquishment” and is driven primarily by a leader’s desire to develop subordinates' autonomy and skills (Leana, 1987: 228-229).

Second, the conceptual model emerging from our findings suggests that dynamic delegation is most likely to engender reliable performance and the development of junior leaders' skills and knowledge. In contrast, the contingency theories of leadership that dominated the leadership literature during the 1970s focused primarily on leadership behaviors predicted to engender follower satisfaction, commitment, and motivation. Critics have charged (e.g., Yukl, 2006) that leadership researchers have devoted insufficient attention to the potential breadth of leadership effects. Our findings highlight the role that leaders may play in developing their subordinates' knowledge and skills - an outcome likely to grow increasingly important given the 
increasing complexity of work and the decreasing average tenure of employees in the changing workplace of the $21^{\text {st }}$ century (Cappelli, 1999; Cascio, 2003).

And third, our findings suggest a level of dynamism unknown in traditional contingency theories of leadership. The contingency theories of the 1970s urged leaders to match their behaviors to the relatively stable characteristics of the situation (the task and/or their subordinates). Fiedler (1971), for example, argued that leaders should be selected for - or matched to - the prevailing situation, as a function of each leader's persistent and prevailing leadership style (high in consideration or high in initiating structure). House (1971) urged leaders to adapt their leadership behaviors to the persistent and prevailing needs of their individual subordinates. And Hersey and Blanchard (1977) suggested differing levels of task and relationship leader behaviors depending on the maturity level of the follower. In contrast, in the TRU, senior leaders repeatedly and rapidly adapt their enactment of the active leadership role to frequent - even minute-to-minute - changes in task demands (i.e., patient condition in the TRU) and team resources (i.e., the demonstrated competence of junior leaders).

Our description of dynamic delegation in the moment thus evokes the familiar specter of the contingency perspective in leadership theory and research, underscoring its continuing utility. But, our description of dynamic delegation updates the familiar contingency model, as well, shifting its focus to leader delegation to the team, turning up its speed and flexibility, and bringing new attention to the influence of leader behaviors - here, delegation - on team, rather than individual, reliability of task performance and capacity development. Our findings thus suggest a revamped contingency perspective in keeping with recent calls for more flexible, adaptive, and time-sensitive models of leader effectiveness (Kozlowski et al., 1996; Yukl and Lepsinger, 2004). 


\section{The Shared, Ongoing Practice of Dynamic Delegation: Contextual Antecedents and Consequences}

The first vantage point, above, allowed us to outline the contingencies that drive an individual leader's moment-to-moment decision to either delegate or to claim the active leadership role. The second vantage point permits a broader focus, allowing us to consider the TRU context - a context in which dynamic delegation is not an occasional practice of one or a few individuals, but rather the on-going and common behavior of TRU leaders.

The TRU context is rich and multifaceted, distinguished by the diverse occupations of the incumbents, the urgency and the extraordinary consequences of their tasks, the recurring changes in the composition of the teams, the deindividualization and hierarchy of leadership positions, and the values, norms, and traditions that guide the work. Of the numerous elements that define this context, three, we suspect, play a critical role in motivating and enabling the practice of dynamic delegation in the TRU and elsewhere: (a) a deep commitment to the development of the unit's novice members; (b) an equally deep commitment to the production of consistent, high quality work outcomes; and (c) an expert hierarchy of authority. A deep commitment to the development of the unit's novice members motivates senior leaders to delegate the active leadership role to junior leaders, despite senior leaders’ knowledge that they themselves can fulfill the role more easily, efficiently, and seamlessly than can the junior leaders. A deep commitment to the production of consistent, high quality work outcomes motivates senior leaders to retract delegation when they perceive that the team's outcomes would suffer were junior leaders to continue unabated in their leadership of the team. And an expert hierarchy of authority legitimates senior leaders' delegation of authority to, and withdrawal of authority from, those lower in the hierarchy. It facilitates the fluid transfer of authority among unit members 
(Hirschhorn, 1993). In the absence of a commitment to the development of novice leaders, delegation would not occur. In the absence of a commitment to the production of highly reliable work outcomes, the withdrawal of delegation would not occur. And in the absence of a clear, expert hierarchy, neither delegation nor the withdrawal of delegation could occur.

Other elements of the TRU context support dynamic delegation, but they are less critical, we believe, for the practice of dynamic delegation; dynamic delegation may well occur in other settings, beyond the TRU, where these elements are not present. These elements include: (a) structured task performance routines; (b) expert support staff; (c) fixed and sequential time structures; and (d) deindividualization. By enhancing senior and junior leaders' comfort with and confidence in the dynamic delegation process, each of these may facilitate the practice of dynamic delegation. Task performance routines reduce ambiguity, ensuring that delegated tasks, roles, and responsibilities are readily communicated and understood. Expert support staff members provide a confidence-inspiring safety net to "catch" junior members of the team if they fail in performing the novel and challenging tasks delegated to them. Fixed and sequential socialization structures (Van Maanen and Schein, 1979) enhance the predictability of dynamic delegation over time, allowing team members to expect and accept differing degrees of delegation over the course of the residents' and fellows' training. Finally, deindividualization the investment of leadership in positions rather than individual people - facilitates dynamic delegation insofar as it allows participants in the process to see the withdrawal of delegation not as a personal insult to a subordinate’s competence and confidence (Yukl, 2006), but simply as the product of structured relationships within the setting.

The ongoing, shared practice of dynamic delegation, our findings suggest, allows a unit even a unit performing inherently risky tasks, like the TRU - to deliver consistent, reliable 
performance while also developing its novice employees and thus its capacity. A defining characteristic of high reliability organizations is that organizational members cannot adopt trialand-error or experimental learning processes (Rochlin, 1993; Weick, Sutcliffe, and Obstfeld, 1999). Our research findings suggest, however, that the process of dynamic delegation may support constrained trial-and-error learning within a high-risk work context. By delegating authority to junior leaders, senior leaders create “stretch opportunities” (McCauley et al., 1994; McCauley and Brutus, 1998), allowing junior leaders to learn skills in vivo, in part through the commission of relatively small errors. By withdrawing authority from junior leaders, senior leaders take control of challenging tasks when they perceive that the magnitude of the errors that junior leaders might commit is too great. In this way, unit leaders ensure both learning and reliable performance by allowing for small errors while at the same time preventing them from snowballing into large failures.

Dynamic delegation is thus a "dialectic process" allowing a unit to balance "the colliding events, forces, or contradictory values which compete with each other for domination and control” (van de Ven, 1992: 178). Still, it is possible to overstate the extent to which reliability and the development of novices' skills represent contradictory goals. In the TRU, when the workload is heaviest - when there has been a large-scale disaster, such as a major pile-up on the freeway, necessitating many patients' care - the TRU can only provide reliable treatment if senior leaders have, in the preceding days and weeks, actively developed junior leaders’ skills and knowledge. In sum, when a unit is hierarchical, and dedicated both to reliable performance and to the development of its novice members, the shared, ongoing practice of dynamic delegation may flourish, building the unit’s capacity to perform reliably. 


\section{Dynamic Delegation and the Use of Role-Based Bureaucratic Structures and Flexibility- Enhancing Processes in Improvisational Organizations}

The TRU leadership system is at once rigidly hierarchical - even bureaucratic - and fluidly flexible. Dynamic delegation reflects and embodies this seeming paradox. Our third vantage point allows us to explore the dual nature of leadership in the TRU, noting similarities between the highly bureaucratic, yet flexible and adaptive TRU leadership system and the practices and structures of other organizations that "capitalize on the control and efficiency benefits of bureaucracy while avoiding or overcoming the tendencies toward inertia” (Bigley and Roberts, 2001:1281).

Recently, Bigley and Roberts (2001) and Bechky (2006) described two such organizations. Both organizations are, like the TRU, “improvisational.” That is, their membership is fleeting and their tasks are time-sensitive and interdependent. Bigley and Roberts (2001) studied firefighters who join with other firefighters and emergency personnel, outside their own station or department, to combat large-scale fires and other disasters. Bechky (2006) studied the members of film crews who join together, with little or no shared history or organizational membership, to film a video or movie. Echoing a key theme in our findings, both Bigley and Roberts (2001) and Bechky (2006) emphasized that the organizations they studied relied on extensive, formalized, and hierarchical role structures to guide and coordinate role incumbents in performing their high-pressure tasks. As in the TRU, the presence of extensive, formalized, and hierarchical role structures, coupled with limited shared history among role incumbents, leads to a certain deindividualization. That is, organizational members grant one another respect, authority, and information not because of their personal knowledge of one 
another's competencies and personalities, but because of their trust in the wisdom of the role structures (and role allocation decisions) that guide their coordination and collaboration.

Yet, Bigley and Roberts’ (2001) firefighters and Bechky’s (2006) film crews countered, or balanced, their reliance on stable, bureaucratic role-structures by enacting flexibilityenhancing mechanisms that allow role-incumbents to respond to rapidly changing circumstances. Thus, for example, Bigley and Roberts’ (2001) firefighters engaged in “role-switching” (transferring individuals among well-established roles as the emergency situation changes); “constrained improvisation” (giving highly experienced and resourceful subordinates the opportunity for discretion and improvisation in performing their tasks); and "authority migrating” (decoupling individuals’ authority from their formal hierarchical role if they possess relevant knowledge superior to those higher in the role hierarchy). Bechky’s (2006) film crew members learned and negotiated their roles in conversation - specifically, by thanking, admonishing, and joking with one another. And in the treatment teams of the TRU, dynamic delegation served, of course, as a critical flexibility-enhancing mechanism.

Together, our findings, and those of Bigly and Roberts (2001) and of Bechky (2006) suggest that improvisational organizations, whose members come together with little or no prior shared experience to perform complex, urgent, and often highly consequential tasks, may achieve swift coordination and reliable performance by melding hierarchical and bureaucratic role-based structures with flexibility-enhancing processes. Indeed, bureaucratic role-based structures and flexibility-enhancing processes may not be contradictory, or conflicting, but instead complementary. Bureaucratic structures provide sufficient order, clarity, and stability that organizational members may engage in flexibility-enhancing processes without devolving into chaos or conflict. Conversely, flexibility-enhancing processes permit sufficient autonomy 
and adaptability that organizational members may accept bureaucratic structures without giving into inertia, rigidity, or unresponsiveness in the face of changing situational contingencies.

\section{Summary, Implications, and Boundary Conditions}

In sum, we posit that senior leaders engage in dynamic delegation in a contingent fashion, enacting or passing on the active leadership role, dependent on their moment-to-moment perceptions of the urgency and complexity of the task and their confidence in their own skills and those of the junior leaders. Further, we propose that the ongoing, shared practice of dynamic delegation among a unit's leaders is most likely to emerge in units that are hierarchically structured and committed both to reliable performance and to the development of their novice members. And finally, we suggest that the practice of dynamic delegation exemplifies one mechanism to meld and balance bureaucratic structures and flexibility-enhancing processes, yielding swift coordination and high reliability, despite fleeting unit composition and changing task demands.

This multiplex conceptual analysis of dynamic delegation recalls, enriches, extends, and challenges a number of leadership theories and perspectives. It recalls the contingency theories of leadership of the 1970s, but presents a contingency model of delegation - not of initiating structure or of consideration - and suggests a level of dynamism and leader flexibility (Yukl and Lepsinger, 2004) unheard of in the original contingency theories. It draws attention to the context most likely to enable, motivate, and benefit from dynamic delegation, providing one response to critics’ (e.g., House and Aditya, 1997) charges that extant leadership research and theories devote insufficient attention to the context of the leader behaviors they describe. It links the study of leadership - more specifically, of dynamic delegation - to theories and studies of 
hierarchy, bureaucracy, and role-structuring (e.g., Weber, 1947; Hirschhorn, 1993; Bigley and Roberts, 2001).

Our conceptual analysis also points to the boundary conditions of dynamic delegation. Dynamic delegation is most likely to flourish, we have argued, in hierarchically structured settings in which both reliable performance and the development of novices' skills are priorities. Dynamic delegation is thus likely not only in medical training settings, such as the TRU, but in other settings which exemplify these conditions. Doctoral programs are a possible example. So too are apprenticeship programs of many kinds. Professional service firms - consulting firms, law firms, investment firms - are also likely settings for the practice of dynamic delegation. Dynamic delegation may also prove effective in some improvisational settings; the firefighting units’ practices of “constrained improvisation” and "authority migrating” bear some similarity to dynamic delegation. Further, as an increasing number of organizations struggle to perform reliably, to develop novices and newcomers, and to manage turnover in key positions, they may find the practice of dynamic delegation a beneficial leadership approach.

Still, we hasten to note that dynamic delegation is not a panacea. Our findings suggest that dynamic delegation may play a powerful role in fostering reliability of performance and individual learning. But, it is not, we suspect, likely to engender shared learning by the team as a whole, nor team creativity. Edmondson, Bohmer, and Pisano (2001) have eloquently described the challenges that cardiac surgery teams faced in implementing a new surgical procedure. The teams they studied benefited from their leaders' efforts to minimize the status hierarchy and to create a psychologically safe environment for the team's shared learning of new techniques and norms. In contrast, the process of dynamic delegation rests on and reinforces status and expertise differences among team members. The guiding assumption is that senior leaders - 
experts - have knowledge and skills that junior leaders lack. Dynamic delegation is thus not a universal strategy of relevance or benefit to all teams.

\section{Limitations}

Our goal in conducting this study was to gain an in-depth understanding of leadership processes in an extreme action team setting - a microcosm of the changing nature of work, in which dominant theories of leadership might not apply fully. While our findings complement and extend prior understanding of leadership, our study - like all studies - is limited in a number of respects. Our findings are limited, first, by our reliance on data collection in a single organization. We can not and do not claim that the leadership system we documented in the TRU is the best possible leadership system for trauma care or, more generally, for settings in which tasks are urgent, team members vary in their expertise and experience, and the composition of the team changes frequently. Second, our findings describe the TRU leadership system as a whole, summarizing across teams in the TRU. Thus, we did not define, explore, or document, and cannot explain, between-team or between-leader variance in effectiveness. Third, although we sought to use multiple methods to triangulate our findings, we relied most heavily on our interview data. Our observations in the TRU were frequent but unstructured, and limited by our lack of medical training and by the distance we were required to stay from the patient's bedside. And fourth, our findings are inextricably tied to our qualitative approach. Using qualitative methods, we were able to grasp and document the dynamism of the TRU leadership system. Our qualitative approach is, we believe, well-suited to our research goals and to the dynamic setting we studied. As Yin (2002: 13) noted, “case studies are the preferred strategy when 'how' or 'why' questions are being posed, when the investigator has little control over events, and when the focus is on a contemporary phenomenon within some real-life context.” 
But, a different, more structured and quantitative (e.g., survey) research approach might lead to different, but complementary, insights (e.g., Yun, Faraj, and Sims, 2005). Additional research is needed to overcome these limitations and, more specifically, to address critical questions regarding the antecedents and prevalence of dynamic delegation and the effects of dynamic delegation on individual, team, and unit performance and development.

\section{Conclusion}

In an increasing number of organizations, cross-functional teams are the norm, tasks are complex, unpredictable, interdependent, and often urgent, reliable performance is critical, and changes in unit composition are commonplace. We conducted an in-depth qualitative investigation of an extreme exemplar of such a workplace, exploring the roles and functions that leaders perform to guide and coordinate their teams. Our findings underscore the continuing relevance of contingency theories of leadership. At the same time, our findings draw attention to delegation, a leadership behavior little discussed in the extant leadership and here reconceptualized as a dynamic process. Dynamic delegation, our findings suggest, may allow leaders in a hierarchical bureaucracy to share the active leadership role and to thereby achieve two potentially competing goals that are of growing importance to many organizations: the development of their novice members' skills and the reliable performance of urgent, unpredictable, complex, and interdependent tasks. Further, our findings raise the possibility that leadership may be deindividualized in a manner virtually unimaginable from a trait, transformational, or LMX leadership perspective (e.g., Bass,1985; Graen and Uhl-Bien, 1995; Judge et al., 2002; Judge, Piccolo, and Ilies, 2004). When leadership is deindividualized, leaders' behaviors and leaders' relationships with their subordinates may be shaped more by 
organizational roles, traditions, routines, and values than by leaders' distinctive traits and experiences.

Our findings will, we hope, inspire new studies of delegation, of the deindividualization of leadership, of shared leadership structures, and of improvisational work settings in which skilled individuals who may never have worked together before join together as a team to perform complex, interdependent, and time-limited tasks. But, most of all, we hope, that our findings invite additional qualitative and quantitative studies of leadership in team and organizational settings that exemplify the changing nature of work. For decades, we have been well-served by models and studies of leadership that focus on the influence of a single, designated leader in motivating and inspiring his or her followers' efforts, commitment, and performance over time. Yet leadership may surely take other forms and, given the changing nature of work, these forms warrant further conceptual and empirical analysis. 


\section{REFERENCES}

Ashour, A. S., and G. England

1972 “Subordinate’s assigned level of discretion as a function of leader’s personality and situational variables.” Journal of Applied Psychology, 56: 120-123.

Avolio, B. J.

1999 Full Leadership Development: Building the Vital Forces in Organizations. Thousand Oaks, CA: Sage.

Avolio, B. J., Jung, D. I., Murry, W., and N. Sivasubramaniam

1996 "Building highly developed teams: Focusing on shared leadership process, efficacy, trust, and performance.” In M. M. Beyerlein, D. Johnson, and S. T. Beyerlein (eds.), Advances in Interdisciplinary Studies of Work Teams: Vol. 3. Team Leadership: 173-209. Greenwich, CT: JAI Press.

Barley, S. R.

1990 “The alignment of technology and structure through roles and networks.” Administrative Science Quarterly, 35: 61-103.

Bass, B. M.

1985 Leadership and Performance Beyond Expectations. New York: Free Press.

1990 Bass and Stogdill’s Handbook of Leadership: Theory, Research, and Managerial Applications, $3^{\text {rd }}$ ed. New York: Free Press. 
1998 Transformational Leadership: Industry, Military, and Educational Impact. Mahwah, NJ: Erlbaum.

Bauer, T. N., and S. G. Green

1996 “Development of leader-member exchange: A longitudinal test.” Academy of Management Journal, 39: 1538-1567.

Bechky, B. A.

2006 “Gaffers, gofers, and grips: Role-based coordination in temporary organizations.” Organization Science, 17: 3-21.

Bierly, P., and J. Spender

1995 “Culture and high reliability organizations: The case of the nuclear submarine.” Journal of Management, 21: 639-656.

Bigley, G. A., and K. H. Roberts

2001 “The incident command system: Organizing for high reliability in complex and unpredictable environments.“ Academy of Management Journal, 44: 1281-1299.

Cappelli, P.

1999 “Career jobs are dead.” California Management Review, 42: 146-167.

2000 “A market-driven approach to retaining talent.” Harvard Business Review: 103-111. 
Cascio, W. F.

2003 “Changes in workers, work, and organizations.” In W. C. Borman, D. R. Ilgen, and R. J. Klimoski (eds.), Handbook of psychology: Volume 12 industrial and organizational psychology: 401-422. Hoboken, NJ: John Wiley and Sons.

Conger, J. A.

1998 “Qualitative research as the cornerstone methodology for understanding leadership.” Leadership Quarterly, 9: 107-123.

Conger, J. A., and C. L. Pearce

2003 “A landscape of opportunities: Future research on shared leadership.” In C. L. Pearce and J. Conger (eds.), Shared Leadership: Reframing the Hows and Whys of Leadership: 285-303. Thousand Oaks, CA: Sage Publications.

Curall, S. C., T. H. Hammer, L. S. Baggett, and G. M. Doniger

1999 “Combining qualitative and quantitative methodologies to study group processes: An illustrative study of a corporate board of directors.” Organizational Research Methods, 2: 5-36.

Dansereau, F., G. Graen, and J. Haga

1975 “A vertical dyad linkage approach to leadership within formal organizations: A longitudinal investigation of the role making process.” Organizational Behavior and Human Performance, 36: 46-78. 
Denison, D. R., R. Hooijberg, and R. E. Quinn

1995 "Paradox and performance: A theory of behavioral complexity in managerial leadership." Organization Science, 6: 524-541.

Edmondson, A. C., R. M. Bohmer, and G. P. Pisano

2001 “Disrupted routines: Team learning and new technology implementation in hospitals.” Administrative Science Quarterly, 46: 685-716.

Eisenhardt, K. M.

1989 "Building theories from case study research.” Academy of Management Review, 14: 532 550.

Elsbach, K. D., and R. M. Kramer

1996 “Members' responses to organizational identity threats: Encountering and countering the Business Week rankings.” Administrative Science Quarterly, 41: 442-476.

Ely, R. J., and D. A. Thomas

2001 “Cultural diversity at work: The moderating effects of work group perspectives on diversity.” Administrative Science Quarterly, 46: 229-273.

Fiedler, F. E. 
1964 “A contingency model of leadership effectiveness.” In L. Berkowitz (ed.), Advances in Experimental Social Psychology. NY: Academic Press.

1967 A Theory of Leadership Effectiveness. NY: McGraw-Hill.

Glaser, B. G., and A. L. Strauss

1967 The Discovery of Grounded Theory: Strategies for Qualitative Research. New York: Aldine de Gruyter.

Graen, G. B., and M. Uhl-Bien

1995 "Relationship-based approach to leadership: Development of leader-member exchange (LMX) theory of leadership over 25 years: Applying a multi-level multi-domain perspective.” Leadership Quarterly, 6: 219-247.

Hackman, J. R., and R. Wageman

2005 “A theory of team coaching.” Academy of Management Review, 30: 269-287.

Hall, D. T., and J. E. Moss

1998 “The new protean career contract: Helping organizations and employees adapt.” Organizational Dynamics, 26: 22-38.

Hersey, P., and K. H. Blanchard

1977 The management of organizational behavior, $4^{\text {th }}$ edition. Englewood Cliffs, NJ: Prentice Hall. 
Hirschhorn, L.

1993 “Hierarchy versus bureaucracy: The case of a nuclear reactor.” In K. H. Roberts (ed.), New Challenges to Understanding Organizations: 137-149. New York: Macmillan.

House, R. J.

1971 “A path goal theory of leader effectiveness”. Administrative Science Quarterly, 12: 321338.

House, R., J., and R. N. Aditya

1997 “The social scientific study of leadership: Quo vadis?” Journal of Management, 23: 409473.

Ibarra, $\mathrm{H}$.

1999 "Provisional selves: Experimenting with image and identity in professional adaptation.” Administrative Science Quarterly, 44: 764-791.

Judge, T. A., J. E. Bono, R. Ilies, and M. W. Gerhardt

2002 "Personality and leadership: A qualitative and quantitative review.” Journal of Applied Psychology, 87: 765-780.

Judge, T. A., R. Piccolo, and R. Ilies 
2004 "The forgotten ones?: The validity of consideration and initiating structure in leadership research.” Journal of Applied Psychology, 89: 36-51.

Katz, P.

1999 The Scalpel's Edge: The Culture of Surgeons. Needham Heights, MA: Allyn and Bacon.

Kerr, S., and J. M. Jermier

1978 “Substitutes for leadership: Their meaning and measurement.” Organizational Behavior and Human Performance, 22: 375-403.

Kozlowski, S. W. J., and B. S. Bell

2003 “Work groups and teams in organizations.” In W. C. Borman, D. R. Ilgen, and R. J. Klimoski (eds.), Comprehensive Handbook of Psychology: Industrial and Organizational Psychology, Vol. 12: 333-375. New York: Wiley.

Kozlowski, S. W. J., S. M. Gully, E. Salas, and J. A. Cannon-Bowers

1996 “Team leadership and development: Theory, principles, and guidelines for training leaders and teams.” In M. M. Beyerlein, D. Johnson, and S. T Beyerlein (eds.), Interdisciplinary Studies of Work Teams: Vol. 3. Team Leadership: 253-291. Greenwich, CT: JAI Press.

Leana, C. 
1986 “Predictors and consequences of delegation.” Academy of Management Journal, 29: 754774.

1987 "Power relinquishment versus power sharing: A theoretical classification and empirical comparison of delegation and participation.” Journal of Applied Psychology, 72: 228233.

McCauley, C. D., and S. Brutus

1998 Management Development through Job Experiences: An Annotated Bibliography. Greensboro, NC: Center for Creative Leadership.

McCauley, C. D., M. N. Ruderman, P. J. Ohlott, and J. E. Morrow

1994 “Assessing the developmental components of managerial jobs.” Journal of Applied Psychology, 79: 544-560.

McGrath, J. E.

1962 Leadership Behavior: Some Requirements for Leadership Training. Washington DC: U.S. Civil Service Commission.

Miles, M. B., and A. M. Huberman

1984 Qualitative Data Analysis: A Source Book of New Methods. Beverly Hills, CA: Sage.

Miner, A., P. Bassoff, and C. Moorman 
2001 “Organizational improvisation and learning: A field study.” Administrative Science Quarterly, 46: 304-337.

Morgeson, F. P.

2005 "The external leadership of self-managing teams: Intervening in the context of novel and disruptive events.” Journal of Applied Psychology, 90: 497-508.

Pearce, C. L., and J. A. Conger

2003 Shared Leadership: Reframing the Hows and Whys of Leadership. Thousand Oaks, CA: Sage Publications.

Pearce, C. L., and H. P. Sims

2002 "The relative influence of vertical vs. shared leadership on the longitudinal effectiveness of change management teams.” Group Dynamics: Theory, Research, and Practice, 6: 172-197.

Perlow, L.

1998 "Boundary control: The social ordering of work and family time in a high-tech corporation.” Administrative Science Quarterly, 43: 328-357.

Perrow, C.

1984 Normal Accidents: Living with High Risk Technologies. New York, NY: Basic Books. 
Pratt, M. G.

2000 "The good, the bad, and the ambivalent: Managing identification among Amway distributors.” Administrative Science Quarterly, 45: 456-493.

Quinn, R. E.

1984 “Applying the competing values approach to leadership: Toward an integrative framework.” In J. G. Hunt, D. M. Hosking, C. A. Schriesheim, and R. Stewart (eds.), Leaders and Managers: International Perspectives on Managerial Behavior and Leadership: 10-27. NY: Pergamon.

Roberts, K. H.

1990 "Some characteristics of one type of high reliability organization.” Organizational Science, 1: 160-176.

Rochlin, G.

1993 “Defining 'high reliability’ organizations in practice: A taxonomic prologue.” In K. H. Roberts (ed.), New Challenges to Understanding Organizations: 11-32. New York: Macmillan.

Schein, E. H.

1991 Organizational culture and leadership. San Francisco, CA: Jossey-Bass

Schriesheim, C. A., S. L. Castro, and C. C. Cogliser

1999 “Leader-member exchange (LMX) research: A comprehensive review of theory, measurement and data analytic practices.” Leadership Quarterly, 10: 63-113. 
Spradley, J. P.

1979 The Ethnographic Interview. NY: Holt, Rinehart, and Winston.

Strauss, A., and J. M. Corbin

1990 Basics of qualitative research: Grounded theory procedures and techniques. Newbury Park, CA: Sage.

Sundstrom, E., K. P. De Meuse, and D. Futrell

1990 “Work teams: Applications and effectiveness.” American Psychologist, 45: 120-133.

van de Ven, A. H.

1992 "Suggestions for studying strategy process: A research note.” Strategic Management Journal, 13: 169-191.

Van Maanen, J., and E. G. Schein

1979 “Toward a theory of organizational socialization.” In B. M. Staw and L. L. Cummings (eds.), Research in Organizational Behavior, Vol. 1: 209-264. Greenwich, CT: JAI Press.

Vroom, V. H., and A. G. Jago

1988 The New Leadership: Managing Participation in Organizations. Englewood Cliffs, NJ: Prentice-Hall. 
Vroom, V. H., and P. W. Yetton

1973 Leadership and Decision-Making. Pittsburgh, PA: University of Pittsburgh Press.

Weber, $\mathrm{M}$.

1947 Max Weber: The Theory of Social and Economic Organization. Translated by A. M. Henderson and T. Parsons. NY: The Free Press.

Weick, K., K. Sutcliffe, and D. Obstfeld

1999 “Organizing for high reliability: Processes of collective mindfulness.” Research in Organizational Behavior, 21: 81-123.

Yin, R. K.

2002 Case study research: Design and methods. Thousand Oaks, CA: Sage Publications.

Yukl, G.

1999 “An evaluation of conceptual weaknesses in transformational and charismatic leadership theories.” Leadership Quarterly, 10: 285-305.

2006. Leadership in Organizations, $6^{\text {th }}$ ed. Upper Saddle River, NJ: Pearson Prentice-Hall.

Yukl, G. A., and P. Fu

1999 “Determinants of delegation and consultation by managers.” Journal of Organizational Behavior, 20: 219-232. 
Yukl, G. A., and R. Lepsinger

2004 Flexible Leadership: Creating Value by Balancing Multiple Challenges and Choices. San Francisco, CA: Jossey Bass.

Yun, S. Faraj, S. and H. P. Sims

2005 “Contingent leadership and effectiveness of trauma resuscitation teams.” Journal of Applied Psychology, 90: 1288-1296.

Zaccaro, S. J., J. A. Gilbert, K. K. Thor, and M. D. Mumford

1991 "Leadership and social intelligence: Linking social perspectiveness and behavioral flexibility to leader effectiveness.” Leadership Quarterly: 2: 317-342.

Zaccaro, S. J., A. L. Rittman, and M. A. Marks

2001 “Team leadership.” Leadership Quarterly, 12: 451-483. 
Table 1: Identity of Team Leader, Leadership Findings, and Criteria for Evaluation

\begin{tabular}{|c|c|c|}
\hline Topic & & Evidence \\
\hline \multirow{3}{*}{$\begin{array}{l}\text { Identity of } \\
\text { Team } \\
\text { Leader }\end{array}$} & \multicolumn{2}{|c|}{$\begin{array}{l}\text { We generally consider two persons to be leaders. One is the trauma attending and } \\
\text { the other is the trauma fellow or chief resident of that team. (A7) }\end{array}$} \\
\hline & \multicolumn{2}{|c|}{$\begin{array}{l}\text { I would say, when you have a more hands-off attending, the leader becomes the } \\
\text { fellow in my experience in the severe trauma cases. In trauma cases where it's } \\
\text { really more routine and not as critical, the resident is really the team leader, the } \\
\text { resident who is taking that patient really is the leader. (R3) }\end{array}$} \\
\hline & \multicolumn{2}{|c|}{$\begin{array}{l}\text { Who's the leader in the bay...that pretty much includes everybody. That is part } \\
\text { of patient care here, but in general it is either the attending, the fellow, or the } \\
\text { resident. (R2) }\end{array}$} \\
\hline \multirow[t]{10}{*}{$\begin{array}{l}\text { Leadership } \\
\text { Behaviors }\end{array}$} & \multirow{3}{*}{$\begin{array}{l}\text { Strategic } \\
\text { Direction }\end{array}$} & $\begin{array}{l}\text { Well, in a perfect world the leader would have their eye on the big } \\
\text { picture, coordinating the entire plan of care for the patient. (A1) }\end{array}$ \\
\hline & & $\begin{array}{l}\text { Being able to lead people and being able to say - "okay, this is our } \\
\text { overall goal, this is where we need it to be, this is the path that we } \\
\text { need to take" - is more important than doing it all yourself. (A3) }\end{array}$ \\
\hline & & $\begin{array}{l}\text { The first thing that I try and do is staging, direction, and telling who } \\
\text { to do what. (F7) }\end{array}$ \\
\hline & \multirow{3}{*}{ Monitor } & $\begin{array}{l}\text { I think in terms of monitoring, you have the Ronald Reagan slogan: } \\
\text { trust but verify. So the responsibility of the attending is to make } \\
\text { sure that everything is as it appears to be on the books. (F2) }\end{array}$ \\
\hline & & $\begin{array}{l}\text { It's kind of interesting because you tell a person, “This is your } \\
\text { patient, you put the line in, you do this, you do that, it is your } \\
\text { patient.” You have given him/her leadership but you are there } \\
\text { saying things like, “Ok. What do you do next? What are you } \\
\text { thinking?” (F1) }\end{array}$ \\
\hline & & $\begin{array}{l}\text { The fellow and the attending have to monitor the team to make sure } \\
\text { that you don't have a goofball trying to do a rescue if he doesn't } \\
\text { know how to do it, but simply wants to. (R11) }\end{array}$ \\
\hline & \multirow{3}{*}{ Hands On } & $\begin{array}{l}\text { As the severity of the injury gets worse, you will see more of an } \\
\text { intervention. If the patient is coding, you will see my hands on, } \\
\text { cutting the patient. I will be hands on. (A2) }\end{array}$ \\
\hline & & $\begin{array}{l}\text { Some attendings are very hands on. And the more hands on an } \\
\text { attending is, the more it takes away from your role as a fellow. And } \\
\text { sometimes that's not good. Sometimes you really want somebody } \\
\text { whose hands on because you don't know what the hell to do. (F5) }\end{array}$ \\
\hline & & $\begin{array}{l}\text { When things are going sour, when the patient is crashing, or when } \\
\text { the residents can't accomplish something, that is when I step in. I } \\
\text { take off my jacket and get my hands dirty. (F6) }\end{array}$ \\
\hline & Teaching & $\begin{array}{l}\text { It is not hard to be a good leader, you just step in and take over in } \\
\text { that sense, but it is hard to be a good educator. It is hard to fulfill } \\
\text { that function of protecting the patient and helping them at the same } \\
\text { time. (A5) }\end{array}$ \\
\hline
\end{tabular}




\begin{tabular}{|l|l|}
\hline & $\begin{array}{l}\text { I say, "Okay, now watch me do this. I did this intervention. This is } \\
\text { the response.” It's like, “See one, do one, teach one.” They see you } \\
\text { doing it, they're gonna do it, and then later on they'll be able to teach } \\
\text { somebody else to do it. (F4) }\end{array}$ \\
\hline $\begin{array}{l}\text { The second you're an intern, you're teaching medical students. I } \\
\text { mean, that's just how medical education is. As soon as you finish, } \\
\text { you become a teacher to someone. And there's always somebody to } \\
\text { teach you as well. (F7) }\end{array}$ \\
\hline
\end{tabular}


Table 2: Hierarchy and Dynamic Delegation

\begin{tabular}{|c|l|}
\hline Topic & \multicolumn{1}{c|}{ Evidence } \\
\hline \multirow{5}{*}{ Hierarchy } & $\begin{array}{l}\text { They really try to put a large emphasis on the hierarchy and the senior is } \\
\text { always responsible for the junior and the junior is always responsible for } \\
\text { the med. student. (R6) }\end{array}$ \\
\cline { 2 - 3 } & $\begin{array}{l}\text { This is how you discuss surgeons: We're a pack of wolves. We're not a } \\
\text { pack of dogs. This means we are all wild. There is a hierarchy. } \\
\text { Somebody is in charge and that person hunts first, kills first, but we hunt } \\
\text { in a pack. (F1) }\end{array}$ \\
\hline & $\begin{array}{l}\text { How many years you have trained: You win if you have more than the } \\
\text { other person. Period. (F3) }\end{array}$ \\
\cline { 2 - 2 } & $\begin{array}{l}\text { It is military in the sense of how strong the hierarchy is. (A3) } \\
\text { Do for each individual patient, the resident was basically in charge to the } \\
\text { point where they were either beyond their capabilities of dealing with } \\
\text { that particular patient, or they needed some guidance and that's when I } \\
\text { would step in. That is when my leadership role takes over. The same } \\
\text { goes, I would think, for an attending. If he would see that I was beyond } \\
\text { my capabilities, I was missing a certain aspect that he thought was } \\
\text { important, then he would step in and bring that to my attention. So that is } \\
\text { the way that I let the leadership role kind of evolve, starting from a } \\
\text { resident's standpoint. (F4) }\end{array}$ \\
\cline { 2 - 3 } & $\begin{array}{l}\text { You can take leadership in different ways - some direct, some indirect. } \\
\text { If I've seen people keying in on me to provide leadership, and I'm trying } \\
\text { to bring the fellow along, I will say to the fellow, "What do you think?" } \\
\text { Or, if it's going the wrong way, I become very eager. My voice becomes } \\
\text { very black and white and they know we are going to do it this way. It is } \\
\text { clearly emphatic. (A3) }\end{array}$ \\
\cline { 2 - 3 } & $\begin{array}{l}\text { It's not so much that they push you out of the way or take the tube out of } \\
\text { your hands or whatever. They'll start speaking up more and then } \\
\text { automatically, people recognize them as someone of a higher level, so } \\
\text { they must be in charge of the resuscitation. (R9) }\end{array}$ \\
\hline
\end{tabular}


Table 3: Patient Condition, Individual Differences, Confidence in Self and Others

\begin{tabular}{|c|c|}
\hline Topic & Evidence \\
\hline \multirow{3}{*}{$\begin{array}{l}\text { Patient } \\
\text { Condition }\end{array}$} & $\begin{array}{l}\text { If the patient is not as critical, then I sit back more and allow the resident and the } \\
\text { fellow to kind of work the patient up and then tell me what they want to do and I } \\
\text { can either tell them yes or no. (A2) }\end{array}$ \\
\hline & $\begin{array}{l}\text { If something goes wrong or the patient is critically ill, then the fellow moves in } \\
\text { there, and they'll move that person out of the way pretty quickly. And if it is } \\
\text { really, really wrong, then the attending will move in. (A5) }\end{array}$ \\
\hline & $\begin{array}{l}\text { I guess if it's a really sick patient -like a thorocotomy - then, yeah, they'll step } \\
\text { in, and they're the ones running it and doing it. I think that just comes down to } \\
\text { experience. I've seen a number. I've done one. I definitely wouldn't be } \\
\text { comfortable saying, "You know, you can just go step back over there. I've got } \\
\text { it." (R7) }\end{array}$ \\
\hline \multirow{3}{*}{$\begin{array}{l}\text { Individual } \\
\text { Differences }\end{array}$} & $\begin{array}{l}\text { There are more passive fellows and then there are very active and aggressive } \\
\text { fellows that really from the get-go want to be in the ultimate leader role and do } \\
\text { everything possible to be complete, to be compulsive, to be pushing care } \\
\text { forward. So there are some different personalities and it is an interactive thing. } \\
\text { And the same is true I think with attendings. My leadership style is maybe more } \\
\text { strict than others' styles. (A4) }\end{array}$ \\
\hline & $\begin{array}{l}\text { Everybody is a little different. Everyone has their individual styles in terms of } \\
\text { how they want to go about playing their role as a leader. Some are more hands } \\
\text { on, some are more apt to delegate than others, and some are more of an educator } \\
\text { than others. (F4) }\end{array}$ \\
\hline & $\begin{array}{l}\text { Well, that depends on the attending you're working with. Some attendings like } \\
\text { to be more hands-on than others. My first week here, I worked with an attending } \\
\text { who liked to do everything himself. Our attending this week is much more } \\
\text { hands-off, you know? He may not even have gloves on, and is standing back } \\
\text { and letting us do what needs to be done and making suggestions but not really } \\
\text { getting too hands-on. (R3) }\end{array}$ \\
\hline \multirow{3}{*}{$\begin{array}{c}\text { Confidence } \\
\text { in Others }\end{array}$} & $\begin{array}{l}\text { Some of the residents we work with have technically more years of experience } \\
\text { than the fellows have. It happens every once in a while. And you see one and } \\
\text { know that he is going to do a good job. You watch a couple of times and you } \\
\text { can trust him. Other ones, especially the ones that start in July, are a doctor for } \\
\text { five hours before they are trying to manage a trauma patient. In that case, I am } \\
\text { not going to walk away. I am not going to let them put an IV in by themselves. } \\
\text { (F3) }\end{array}$ \\
\hline & $\begin{array}{l}\text { You figure out who is competent really fast. And how do you figure it out? You } \\
\text { could probably figure it out in the first } 2 \text { days and not even see them do all that } \\
\text { much. For example, by how often their superiors agree with what their plan is or } \\
\text { whether they even have a plan and just a general air of competence. (R2) }\end{array}$ \\
\hline & $\begin{array}{l}\text { You learn quickly and get a grasp on the knowledge base of an individual in } \\
\text { medicine. It doesn't take long after you talk to someone or have lunch with } \\
\text { someone ... You realize what they know or don't know. And you get a grasp } \\
\text { very quickly of competency, which then tells you how much range you can give } \\
\text { someone when it comes to resuscitating a patient. (A8) }\end{array}$ \\
\hline
\end{tabular}




\begin{tabular}{|c|l|}
\hline \multirow{3}{*}{$\begin{array}{c}\text { Confidence } \\
\text { in Self }\end{array}$} & $\begin{array}{l}\text { I tell my residents all the time, “Whatever you screw up, I can fix.” If I could } \\
\text { not do that, then I wouldn't let them do it. That's just part of it, if I can't do that, } \\
\text { then I can't let them be doing that procedure. So anything that I'm watching } \\
\text { them do, I can do better. If you can't do that, then you should be doing } \\
\text { something else. (A6) }\end{array}$ \\
\cline { 2 - 2 } & $\begin{array}{l}\text { Another particular attending not only doesn't want the resident to do it, he } \\
\text { doesn't want the fellow to do it. He goes in there and does it himself. Maybe he } \\
\text { wants to do it and because he doesn't feel comfortable enough to let someone } \\
\text { else do what he is not comfortable with doing himself. (R5) }\end{array}$ \\
\hline
\end{tabular}


Table 4: Enabling Characteristics

\begin{tabular}{|c|c|}
\hline Topic & Evidence \\
\hline \multirow{3}{*}{$\begin{array}{l}\text { Routines, } \\
\text { Tradition, } \\
\text { and Values }\end{array}$} & $\begin{array}{l}\text { We've protocolized a lot of things. We have our way of doing it. There are } \\
\text { advantages and disadvantages to that too, but it makes it more clear. So you } \\
\text { can say to somebody, "Okay, that may be the way that you do it at the } \\
\text { University of Akron, but you're not at the University of Akron. You're here and } \\
\text { here's the protocol we use here." There is a little manual that the residents and } \\
\text { fellows get which tells them what to do, so that helps to some extent. (A5) }\end{array}$ \\
\hline & $\begin{array}{l}\text { There's a military structure in surgery where everything has to go through } \\
\text { certain channels and God forbid you try to overstep one. (F6) }\end{array}$ \\
\hline & $\begin{array}{l}\text { As an attending, I try to help transition fellows to an attending status so they } \\
\text { recognize... that it is not what I want, it is what the patient needs that is } \\
\text { important. Quibble doesn't matter at this point. I can take that to a meeting a } \\
\text { week later or whatever. All that matters is the patient. How can I maximize } \\
\text { efficiency in patient care? (A4) }\end{array}$ \\
\hline \multirow{3}{*}{ Support Staff } & $\begin{array}{l}\text { The thing that's different about here is that the personnel and the nursing staff } \\
\text { have been here for so long and just know the system. They probably could } \\
\text { manage most of the things downstairs better than some of the junior residents. } \\
\text { (F4) }\end{array}$ \\
\hline & $\begin{array}{l}\text { We have a lot of autonomy as nurses. We can gently tell the docs what we } \\
\text { think. Nurses have more autonomy here than in other areas of the hospital. } \\
\text { The nurses are very experienced here and there's usually so much going on that } \\
\text { you're left to handle things by yourself. The residents are coming here to learn, } \\
\text { but we're here everyday. (N1) }\end{array}$ \\
\hline & $\begin{array}{l}\text { I think that what is unique about the hospital is that it's a nurse run hospital. } \\
\text { From the bottom to the top, the nurses really keep things organized. They make } \\
\text { sure everything is done. In an appropriate way and in an appropriate amount of } \\
\text { time, make sure everything is done in a pattern. (R10) }\end{array}$ \\
\hline \multirow{3}{*}{$\begin{array}{l}\text { Time } \\
\text { Awareness }\end{array}$} & $\begin{array}{l}\text { Well, I think if the residents are not getting along, then it's a problem, but like I } \\
\text { said, the residents are here for a month or two months at a time. The rest of us } \\
\text { live here. We do things the way we do things every day. And they're here for } \\
\text { a month and they go back to Iowa or Ohio or wherever they came from. (N2) }\end{array}$ \\
\hline & $\begin{array}{l}\text { Most of the residents enjoy getting the patients and doing the procedures. But, } \\
\text { there's one resident on our team who's been here going on two months. He's } \\
\text { just counting down the days. Being on call every third night and staying awake } \\
\text { the whole night is pretty challenging. (R5) }\end{array}$ \\
\hline & $\begin{array}{l}\text { That is a well known prescription for corporate advancement and that is } \\
\text { essentially what you are doing here. It is much more regimented here than in } \\
\text { the corporate world where you get a promotion every one to five years. Here } \\
\text { you have very specific time periods where you know exactly what you are } \\
\text { going to be doing a year from now in the next year. (F2) }\end{array}$ \\
\hline
\end{tabular}

